\title{
Decomposition Analysis of Global Water Supply-Demand Balances Focusing on Food Production and Consumption
}

\author{
Yohei Yamaguchi ${ }^{1, *}$, Naoki Yoshikawa ${ }^{2}$, Koji Amano ${ }^{3}$ and Seiji Hashimoto ${ }^{2}$ \\ 1 Graduate School of Science and Engineering, Ritsumeikan University, Kusatsu 525-8577, Japan \\ 2 College of Science and Engineering, Ritsumeikan University, Kusatsu 525-8577, Japan; \\ n-yoshik@fc.ritsumei.ac.jp (N.Y.); shashimo@fc.ritsumei.ac.jp (S.H.) \\ 3 College of Gastronomy Management, Ritsumeikan University, Kusatsu 525-8577, Japan; \\ amano@se.ritsumei.ac.jp \\ * Correspondence: y-ymagch@fc.ritsumei.ac.jp
}

Citation: Yamaguchi, Y.; Yoshikawa, N.; Amano, K.; Hashimoto, S. Decomposition Analysis of Global Water Supply-Demand Balances Focusing on Food Production and Consumption. Sustainability 2021, 13, 7586. https://doi.org/10.3390/ su13147586

Academic Editor: Ali Torabi Haghighi

Received: 13 May 2021

Accepted: 30 June 2021

Published: 7 July 2021

Publisher's Note: MDPI stays neutral with regard to jurisdictional claims in published maps and institutional affiliations.

Copyright: (c) 2021 by the authors. Licensee MDPI, Basel, Switzerland. This article is an open access article distributed under the terms and conditions of the Creative Commons Attribution (CC BY) license (https:// creativecommons.org/licenses/by/ $4.0 /)$.

\begin{abstract}
Food production and consumption require large amounts of freshwater. There is no literature on the decomposition analysis of the intensities of water supply-demand balances (water balance intensities) for each country worldwide. The aim of this study is to evaluate the water balance intensities and elucidate the promoting factors and offset factors of water balance intensities for each country worldwide, focusing on food supply-demand balances and considering food trade balances on a global scale. The modified Laspeyres index method is applied to both a production-based water balance index $\left(W B I^{P B}\right)$ and a consumption-based water balance index $\left(W B I^{C B}\right)$. The major promoting factor for the $W B I^{P B}$ is the renewable freshwater resources, whereas the major offset factor is the produced item preference. The major promoting factor for the $W B I^{C B}$ is the consumed item preference, whereas the major offset factor is the producing area preference. Improving irrigation efficiencies of rice and cereals is effective because rice requires the largest blue water footprint intensities, considering irrigation efficiency on a calorie content basis in all of the items, whereas cereals are the largest share of calorie-based production quantities in all of the items worldwide. This study provides the foundation for decreasing water balance intensities regarding food production and consumption.
\end{abstract}

Keywords: water balance index; modified Laspeyres index method; water footprint; blue water; food supply-demand balances; global analysis

\section{Introduction}

Food production and consumption are essential for human life but require large amounts of freshwater. The agricultural sector consumes the largest amount of water $\left(2658 \mathrm{~km}^{3} /\right.$ year), accounting for approximately $70 \%$ of the global total water withdrawal [1]. However, freshwater resources tend to be unevenly distributed in water-rich regions worldwide. It is said that the direct trade of freshwater resources between waterrich and water-poor regions is impossible due to the costs incurred in long-distance transportation [2]. Thus, trading food could be an important option for water-poor regions to compensate for their food shortage, which leads to an unintentional increase in freshwater requirements for food-producing regions.

The International Organization for Standardization introduced the concept of water footprint, which makes it possible to quantify the potential impact of water use and pollution based on the idea of a life cycle assessment [3]. Most goods and services are consumed by households, businesses, and offices at the final demand stages and finally arrive at the end-of-life stages via raw material, processing, distribution, and retail sale stages. The water requirements of goods and services are estimated by summarizing the water consumption for all stages. The Water Footprint Network proposed three types of water footprint: green, blue, and gray [4]. Green water originates from precipitation, does 
not run off and is not immediately restored to surface water and groundwater. Some of the restored water is consumed as blue water, which is artificially supplied as irrigation water to compensate for the shortfalls in green water. Gray water is the hypothetical volume of freshwater required to dilute the pollutant loads in existing ambient water quality standards to natural background concentrations [4]. To evaluate water supply-demand balances, a water stress index is defined as the ratio of annual water withdrawals to annual renewable water resources [5], and it has been used in many previous studies and defined in various forms [6,7]. Blue water is used to evaluate the water stress index [8]. Water stress is generally suitable for the evaluation of water demand on a production basis and is unsuitable for that on a consumption basis.

Decomposition analysis is a useful tool for elucidating the factors of change between two periods or objects. There are two techniques for decomposition analyses: index decomposition analysis (IDA) and structure decomposition analysis (SDA). The former is applied to aggregate data at the sector level, whereas the latter is applied to the inputoutput model [9]. It is important to improve the problem of residual terms, interpreted as the amount of change between two or more factors, to show a reliable decomposition result. As perfect decomposition techniques, various models have been proposed in the literature, such as the log-mean Divisia index (LMDI) method I and II [10], refined Laspeyres index (RLI) method [11-13], and modified Laspeyres index (MLI) method [14,15]. Based on the assumption that there is no residual term and the factors of change are only timedependent, the LMDI method is often used. In contrast, the RLI method is fairly complex when applied to more than two factors [16]. In addition, it has the over- or under-estimation problems caused by the attribution and distribution methods of residual terms $[14,15]$. Although the MLI method has limitations of the same complicity as the RLI method, it can be applied to negative values and to improve the attribution and distribution problems of the RLI method.

In the aforementioned methods, IDA and SDA are commonly used together when evaluating the water footprint. The LMDI method, a type of IDA, was used to analyze changes in the water footprint of crop production in Beijing [17], in the driving force analysis of the agricultural water footprint in China [18], and to estimate regional irrigation water demand and driving factor effects in the Heihe River basin [19]. The SDA was used to analyze changes in Beijing's water footprint [20], changes in the sectoral water footprint in China [21], and the driving force of the water footprint under the rapid urbanization process for Zhangye City in China [22]. The SDA was also applied to identify the hydroclimatic and socioeconomic forces of water scarcity in Beijing [23]. All the studies cited here were based on temporal data during specific periods. Studies have been conducted on the spatial decomposition analysis of water intensity in China [24]. To the best of the author's knowledge, there is no literature on the decomposition analysis of the intensities of water supply-demand balances (water balance intensities) for each country worldwide, focusing on food supply-demand balances and considering food trade balances on a global scale.

This study aims to evaluate water balance intensities and elucidate the promoting and offset factors of water balance intensities for each country on a global scale. This study provides the foundation for decreasing water balance intensities regarding food production and consumption based on water resource management.

\section{Materials and Methods}

2.1. Food Supply-Damand Balances Considering Food Trade Balances

The equation for food supply-demand balances is as follows:

$$
P R O_{c j}+I Q_{c j}+S V_{c j}=D S Q_{c j}+E Q_{c j}
$$

where subscripts $c$ and $j$ represent the target country and food item, respectively. $P R O_{c j}$ is the production quantity, $I Q_{c j}$ is the import quantity, $S V_{c j}$ is the amount of stock variation, $D S Q_{c j}$ is the domestic supply quantity, and $E Q_{c j}$ is the export quantity of item $j$ for country c. $I Q_{c j}$ is the sum of $I Q_{i j k}$ in producing country $k$, whereas $E Q_{c j}$ is the sum of $E Q_{i j k}$ in 
consuming country $i$. Raw data of each category are used after calculating the three-year average from 2009 to 2011 to employ as the yearly reference data for each category. Here, $I Q_{i j k}$ and $E Q_{i j k}$ are taken from the food trade balance matrices for each item, which were calculated in our previous study [25]. Before calculating $I Q_{c j}$ and $E Q_{c j}$, each component of the food trade balance matrices is adjusted by using the RAS method [26] to match the sum of import quantities with that of export quantities for each food item on a global scale.

In the commodity balance sheets of the Food and Agriculture Organization Corporate Statistical Database (FAOSTAT), $D S Q_{c j}$ is the sum of six consumption categories: feed, processed materials, losses, food supply quantities, seeds, and other uses [27]. In this study, feed and processed materials are considered as intermediate demands, whereas food supply quantities and losses are classified into final demands and composed of food consumption. Losses are interpreted as losses caused during storage or technical losses caused when transforming the primary commodities into processed products, excluding losses occurring during the pre-harvest and harvesting stages and deriving from edible or inedible waste in the household [27]. Seeds are the amounts of the commodity used for reproductive purposes, such as seed of sugarcane plant, hatching eggs, and fish bait [27]. Other uses include the amounts of the commodity mainly consumed by tourists and used for manufacturing in non-food purposes such as oil for soap [27].

\subsection{Production-Based and Consumption-Based Blue Water Requirements}

In this study, only blue water is targeted. Surface and ground water play a role of a supply source of blue (irrigation) water to supplement the shortage of green water (rainwater). From this viewpoint, focusing on blue water requirements is suitable to simulate water balance intensities. Thus, green water is excluded from the evaluation target. The blue water requirement is calculated in two manners: a blue water requirement on a production basis and a consumption basis $\left(W R^{P B}\right.$ and $W R^{C B}$, respectively) defined as follows:

$$
\begin{gathered}
W R_{k j}^{P B}=P R O_{k j} \times \frac{W F I_{k j}}{I R E_{k j}} \\
W R^{C B}{ }_{i j k}=C O M_{i j k} \times \frac{W F I_{k j}}{I R E_{k j}},
\end{gathered}
$$

where superscripts $P B$ and $C B$ represent production-based simulation and consumptionbased simulation, respectively. $W R^{P B}{ }_{k j}$ is the $W R^{P B}, P R O_{k j}$ is the production quantity, $W F I_{k j}$ is the water footprint intensity, and $I R E_{k j}$ is the irrigation efficiency of item $j$ for producing country $k$. In Equation (3), $W R^{C B}{ }_{i j k}$ is the $W R^{C B}$ and $C O M_{i j k}$ is the food consumption of item $j$ between consuming country $i$ and producing country $k$.

$C O M_{i j k}$ is classified into two patterns based on the relationship between consuming country $i$ and producing country $k$, namely, $i=k$ and $i \neq k$ :

$$
\begin{gathered}
C O M_{i j k}=P R O_{i j}+S V_{i j}-F E_{i j}-P R C_{i j}-S E_{i j}-O U_{i j}(i=k) \\
C O M_{i j k}=I Q_{i j k}-E Q_{i j k}(i \neq k),
\end{gathered}
$$

where $P R O_{i j}$ is the production quantity, $S V_{i j}$ is the amount of stock variation, $F E_{i j}$ is the amount of feed, $P R C_{i j}$ is the amount of processed materials, $S E_{i j}$ is the amount of seeds, and $O U_{i j}$ is the amount of other uses of item $j$ for consuming country $i$. Here, $\left(I Q_{i j k}-E Q_{i j k}\right)$ is defined as the net trade quantity calculated by subtracting the export quantity from the import quantity for each country on a per capita basis. The net import and export quantities are defined as $\left(I Q_{i j k}-E Q_{i j k}\right)$ with $I Q_{i j k} \geq E Q_{i j k}$ and $I Q_{i j k}<E Q_{i j k}$, respectively. If $I Q_{i j k} \geq E Q_{i j k}$, the water footprint intensity of production countries is applied to $W F I_{i j k}$; otherwise $\left(I Q_{i j k}<E Q_{i j k}\right)$, that of consumption countries is applied to $W F I_{i j k}$. The irrigation efficiency is evaluated in the same way as the $W R^{P B}$.

For agricultural crops, only direct water consumption during the cultivation stage is included. For livestock products, direct water consumption during the rearing stage of 
livestock, such as drinking water and service water to maintain a rearing environment, and feed crops for livestock during the cultivation stage are included. These stages consist of a system boundary for water footprint simulation. Here, the aforementioned types of water consumption are originally included in the water footprint intensities. The intermediate demand composed of feed and processed materials is excluded from our simulation because an overestimation could be caused by a double counting of the water footprint. Thus, the final demand, composed of food supply quantities and losses, is targeted. In addition, seeds and other uses are excluded from the simulation because seeds are considered as a type of upstream indirect water consumption during the cultivation stage for each agricultural crop, and other uses are not inconsistent in the system boundary. Thus, feed, processed materials, seed, and other uses are subtracted from the sum of production quantities and the amount of stock variation in the Equation (4).

$W F I_{k j}$ and $I R E_{k j}$ mainly refer to the literature values (Refs. [28,29], respectively) of item $j$ for the producing country or for area $k$. Missing data on $W F I_{k j}$ are replaced with the water footprint intensities of neighboring countries for each item, simple average values of 23 regions for each item, calculated using the literature values for the applicable countries, or literature values of the world average for each item [28]. $I R E_{k j}$ for rice is uniformly set as 1.0 , whereas $I R E_{k j}$ for non-rice items is set as the irrigation efficiency of non-rice items for each region. $I R E_{k j}$ of Middle Africa and North America are set as irrigation efficiencies on a simple regional average for each applicable area. To avoid overestimation due to transit trades, the exported blue water footprint intensity of item $j$ for consuming country $i$ on a weighted average is defined. The weights are the production and net import quantities of item $j$ for producing country $k$.

\subsection{Production-Based and Consumption-Based Water Balances Indices}

In this study, water balance intensities are evaluated by using two water balance indices: a production-based water balance index $\left(W B I^{P B}\right)$ and a consumption-based water balance index $\left(W B I^{C B}\right)$. The former can evaluate water balance intensities based on production by assigning water requirements to producing countries, whereas the latter can evaluate water balance intensities based on consumption by assigning water requirements to consuming countries. Consumption is roughly calculated by adding production and subtracting exports from imports. Based on a comparison between the two indices, it is expected that the difference in water balance intensities between the production and consumption sides can be quantitatively evaluated.

The $W B I^{P B}$ and $W B I^{C B}$ are defined as follows:

$$
\begin{gathered}
W B I_{k}^{P B}=\frac{\sum_{j}\left(W R_{k j}^{P B}\right)}{T R W R_{k} \times \frac{A W W_{k}}{T W W_{k}}} \\
W B I_{i}^{C B}=\frac{\sum_{k} \sum_{j}\left(W R^{C B}{ }_{i j k}\right)}{T R W R_{i} \times \frac{A W W_{i}}{T W W_{i}}},
\end{gathered}
$$

where $W B I^{P B}{ }_{k}$ is the $W B I^{P B}$ of producing country $k$, and $W B I^{C B}{ }_{i}$ is the $W B I^{C B}$ of consuming country $i$. $T R W R_{k}$ and $T R W R_{i}$ are the total renewable water resources (TRWR's) of producing country $k$ and consuming country $i$, respectively. $A W W_{k}$ and $A W W_{i}$ are the agricultural water withdrawal $(A W W)$ of producing country $k$ and consuming country $i$, respectively. $T W W_{k}$ and $T W W_{i}$ are the total water withdrawal (TWW) of producing country $k$ and consuming country $i$, respectively. For the TRWR's, $A W W$, and TWW, missing data are replaced with data from the nearest period of the reference year (2010). Countries with no data for the nearest period are excluded from the target countries of this study.

$W B I^{P B}{ }_{k}$ and $W B I^{C B}{ }_{i}$ are evaluated in terms of five intensity categories as follows: very low intensity $(W B I<0.1)$, low intensity $(0.1 \leq W B I<0.2)$, moderate intensity $(0.2 \leq W B I<0.4)$, high intensity $(0.4 \leq W B I<0.8)$, and very high intensity $(W B I \geq 0.8)$ 
The five intensity categories of both indices follow those of the water stress index in a previous study [30].

2.4. Decomposition Analysis of Production-Based and Consumption-Based Water Balances Indices 2.4.1. Decomposed Factors of Production-Based Water Balance Index

To conduct a decomposition analysis, the difference in the $W B I^{P B}$ between each country's value and the standard value is defined as follows:

$$
\begin{gathered}
\Delta W B I^{P B}{ }_{k}=W B I^{P B}{ }_{k}-W B I^{P B}{ }_{0 k} \\
=\sum_{j}^{N_{j k}}\left(\Delta W B I_{k j 1}^{P B}+\Delta W B I_{k j 2}^{P B}+\Delta W B I_{k j 3}^{P B}+\Delta W B I_{k j 4}^{P B}+\Delta W B I_{k j 5}^{P B}\right),
\end{gathered}
$$

where subscript zero represents the standard value. $\triangle \mathrm{WBI}^{P B}{ }_{k}$ is the difference in the $W B I^{P B}$ for producing country $k$, and $W B I^{P B}{ }_{0 k}$ is the standard value of the $W B I^{P B}$ for producing country $k . \triangle W B I^{P B}{ }_{k j n}(n=1,2,3,4,5$, where $n$ is the number of factors $)$ is the decomposed factor of item $j$ for producing country $k$. Each factor is defined as follows: $\triangle W B I^{P B}{ }_{k j 1}$ is a renewable freshwater resources factor $\left(\triangle \mathrm{F} 1 \_\mathrm{PB}\right) ; \triangle W B I^{P B}{ }_{k j 2}$ is an industrial structure factor $\left(\triangle \mathrm{F} 2 \_\mathrm{PB}\right) ; \triangle W B I^{P B}{ }_{k j 3}$ is a production scale factor $\left(\triangle \mathrm{F} 3 \_\mathrm{PB}\right) ; \triangle W B I^{P B}{ }_{k j 4}$ is a produced item preference factor $\left(\triangle \mathrm{F} 4 \_\mathrm{PB}\right)$; and $\triangle W B I^{P B}{ }_{k j 5}$ is a water footprint intensity factor ( $\left.\triangle \mathrm{F} 5 \_\mathrm{PB}\right)$. If $\triangle W B I^{P B}{ }_{k j n} \geq 0$, this factor is seen as a promoting factor for water balance intensities (promoting factor); otherwise $\left(\triangle W B I^{P B}{ }_{k j n}<0\right)$, this factor is seen as offset for water balance intensities (offset factor).

$W B I^{P B}{ }_{k}$ is decomposed into five factors as follows:

$$
\begin{gathered}
W B I^{P B}{ }_{k}=\frac{1}{T R W R_{k}} \times \frac{T W W_{k}}{A W W_{k}} \times W R^{P B}{ }_{k} \\
W R^{P B}{ }_{k}=\sum_{j}^{N_{j k}}\left(P R O^{C A L_{k}} \times \frac{P R O^{C A L_{k j}}}{P R O^{C A L_{k}}} \times \frac{W F I_{k j}}{U C F_{j} \times I R E_{k j}}\right),
\end{gathered}
$$

where superscript $C A L$ indicates a calorie-based conversion. $P R O^{C A L}{ }_{k}$ is the calorie-based production quantity of producing country $k, P R O^{C A L}{ }_{k j}$ is the calorie-based production quantity of item $j$ for producing country $k$, and $U C F_{j}$ is the calorie conversion factor of item $j$. In Equations (9) and (10), all of the right terms except for the third term of Equation (10) are calculated on a per capita basis. Each term in both equations is interpreted as follows: $\left(1 / T R W R_{k}\right)$ is the multiplicative number of the TRWR's related to $\Delta \mathrm{F} 1 \_\mathrm{PB}$; $\left(T W W_{k} / A W W_{k}\right)$ is the multiplicative inverse of the ratio of $A W W$ to $T W W$ (agricultural withdrawal rate) related to $\triangle \mathrm{F} 2{ }_{-} \mathrm{PB} ; P R O^{C A L}{ }_{k}$ is the calorie-based production quantity related to $\triangle \mathrm{F} 3 \_\mathrm{PB} ;\left(P R O^{C A L}{ }_{k j} / P R O^{C A L}{ }_{k}\right)$ is the produced item's share related to $\triangle \mathrm{F} 4 \_\mathrm{PB}$; and $\left(W F I_{k j} / U C F_{j} / I R E_{k j}\right)$ is the water footprint intensity per calorie content considering the irrigation efficiency related to $\triangle \mathrm{F} 5 \_\mathrm{PB}$.

Calorie conversion factors for 11 items ("Cereals, Other", "Roots, Other", "Sweeteners, Others", "Pluses, Other and products", "Oilcrops, Other", "Oilcrops Oil, Other", "Vegetables, Other", "Citrus, Other", "Fruits, Other", "Spices, Other", and "Meat, Other" in the FAOSTAT) are set as a median of calorie conversion factors for each applicable item. Calorie conversion factors for meats are set as a weighted average of the calorie conversion factor whose weight is the amount of distribution for each applicable meat. The meat distribution is calculated by multiplying the amount of distribution by cuts of meat by the population of Japan. The calorie conversion factors for mutton and goat meat are calculated by the calorie conversion factor for lamb meat by cuts of a part on a simple average due to the lack of data on the amount of distribution for both items. 
$W B I^{P B}{ }_{0 k}$ is calculated as follows:

$$
\begin{gathered}
W B I^{P B}{ }_{0 k}=\frac{1}{T R W R_{0}} \times \frac{T W W_{0}}{A W W_{0}} \times W R^{P B}{ }_{0 k} \\
W R^{P B}{ }_{0 k}=\sum_{j}^{N_{j k}}\left(P R O^{C A L}{ }_{0} \times \frac{P R O^{C A L_{0 j k}}}{P R O^{C A L_{0}}} \times \frac{W F I_{0 j}}{U C F_{j} \times I R E_{0 j}}\right),
\end{gathered}
$$

where $T R W R_{0}$ is the standard value of TRWR's and calculated by dividing the sum of $T R W R$ 's for all countries based on the FAO's Global Information System on Water and Agriculture (AQUASTAT) by the global population. $A W W_{0}$ is the standard value of $A W W$ and calculated by dividing the sum of $A W W$ 's for all countries based on the AQUASTAT by the global population. $T W W_{0}$ is the standard value of $T W W$ and calculated by dividing the sum of the TWW's for all countries based on the AQUASTAT by the global population. $P R O^{C A L}{ }_{0}$ and $P R O^{C A L}{ }_{0 j k}$ are the standard values of the calorie-based production quantities and that of item $j$ for producing country $k$, respectively. The former is calculated by adding the calorie-based production quantities for all countries by the global population, whereas the latter is calculated by that of item $j$ for all countries. $W F I_{0 j}$ refers to the literature values [28]. IRE $E_{0 j}$ is the irrigation efficiency on a simple world average and calculated using the literature values for all areas [29]. Here, the correction factor is defined as the ratio of the global population of $\triangle \mathrm{F} 3 \_\mathrm{PB}$ to that of $\triangle \mathrm{F} 1 \_\mathrm{PB}$, which is multiplied by $\Delta \mathrm{F} 1 \_\mathrm{PB}$ to correct the error of $\triangle \mathrm{F} 1 \_\mathrm{PB}$. This error could result from the difference in the global population of $\triangle \mathrm{F} 1 \_\mathrm{PB}$ and that of $\triangle \mathrm{F} 3 \_\mathrm{PB}$. The global population of $\triangle \mathrm{F} 4 \_\mathrm{PB}$ is equal to that of $\triangle \mathrm{F} 3 \_\mathrm{PB}$. Finally, nearly $70 \%$ of all $\mathrm{WBI}^{P B}{ }_{0 k}$ exist at $0.079 \pm 0.033$.

\subsubsection{Decomposition Factors of Consumption-Based Water Balance Index}

To conduct a decomposition analysis, the difference in the $W B I^{C B}$ for each country's value and the standard value is defined as follows:

$$
\begin{gathered}
\Delta W B I^{C B_{i}}=W B I^{C B}{ }_{i}-W B I^{C B}{ }_{0 i} \\
=\sum_{k}^{N_{i j k}} \sum_{j}\left(\Delta W B I_{i j}^{C B}{ }_{i j k 1}+\Delta W B I^{C B}{ }_{i j k 2}+\Delta W B I^{C B}{ }_{i j k 3}+\Delta W B I^{C B}{ }_{i j k 4}+\Delta W B I^{C B}{ }_{i j k 5}+\Delta W B I^{C B}{ }_{i j k 6}\right),
\end{gathered}
$$

where $\triangle W B I^{C B}{ }_{i}$ is the difference in the $W B I^{C B}$ for consuming country $i$ and $W B I^{C B}{ }_{0 k}$ is the standard value of the $W B I^{C B}$ for producing country $k . \triangle W B I^{C B}{ }_{i j k n}(n=1,2,3,4,5,6)$ are six decomposed factors of item $j$ between consuming country $i$ and producing country $k$. Each factor is defined as follows: $\triangle W B I^{C B}{ }_{i j k 1}$ is a renewable freshwater resources factor $\left(\triangle \mathrm{F} 1 \_\mathrm{CB}\right)$; $\triangle W B I^{C B}{ }_{i j k 2}$ is an industrial structure factor $\left(\triangle \mathrm{F} 2 \_C B\right) ; \triangle W B I^{C B}{ }_{i j k 3}$ is a consumption scale factor $\left(\triangle \mathrm{F} 3 \_\mathrm{CB}\right) ; \triangle W B I^{C B}{ }_{i j k 4}$ is a consumed item preference factor $\left(\triangle \mathrm{F} 4 \_C B\right) ; \triangle W B I^{C B}{ }_{i j k 5}$ is a producing area preference factor $\left(\triangle \mathrm{F} 5 \_\mathrm{CB}\right)$; and $\triangle W B I^{C B}{ }_{i j k 6}$ is a water footprint intensity factor $\left(\triangle \mathrm{F} 6 \_\mathrm{CB}\right)$. If $\triangle W B I^{C B}{ }_{i j k n} \geq 0$, this factor is seen as a promoting factor; otherwise $\left(\triangle W B I^{C B}{ }_{i j k n}<0\right)$, it is seen as an offset factor.

$W B I^{C B}{ }_{i}$ is decomposed into six factors as follows:

$$
\begin{gathered}
W B I^{C B}{ }_{i}=\frac{1}{\operatorname{TRWR}_{i}} \times \frac{T W W_{i}}{A W W_{i}} \times W R^{C B}{ }_{i} \\
W R^{C B}{ }_{i}=\sum_{k}^{N_{i j k}} \sum_{j}^{N_{i j}}\left(C O M^{C A L_{i}} \times \frac{\mathrm{COM}^{C A L_{i j}}}{\mathrm{COM}^{C A L_{i}}} \times \frac{C O M^{C A L_{i j k}}}{C O M^{C A L_{i j}}} \times \frac{W F I_{i j}}{U C F_{j} \times I R E_{i j}}\right),
\end{gathered}
$$

where $C O M^{C A L}{ }_{i}$ is the amount of calorie-based consumption of consuming country $i$, $C O M^{C A L}{ }_{i j}$ is the amount of calorie-based consumption of item $j$ for consuming country $i$, and $C O M^{C A L} i j k$ is the amount of calorie-based consumption of item $j$ between consuming country $i$ and producing country $k$. In Equations (14) and (15), all of the right terms except for the fourth term of Equation (15) are calculated on a per capita basis. Each factor 
term in Equations (14) and (15) is interpreted as follows: $\left(1 / T R W R_{i}\right)$ is the multiplicative inverse of the TRWR's related to $\triangle \mathrm{F} 1 \_\mathrm{CB} ;\left(T W W_{i} / A W W_{i}\right)$ is the multiplicative inverse of the agricultural withdrawal rate related to $\triangle \mathrm{F} 2 \_C B ; C O M^{C A L}{ }_{i}$ is the calorie-based food consumption related to $\triangle \mathrm{F} 3 \_C B ;\left(C O M^{C A L}{ }_{i j} / C O M^{C A L}{ }_{i}\right)$ is the consumed item's share related to $\triangle \mathrm{F} 4 \_\mathrm{CB} ;\left(C O M^{C A L}{ }_{i j k} / C O M^{C A L}{ }_{i j}\right)$ is the producing country's share related to $\triangle \mathrm{F} 5 \_C B$; and $\left(W F I_{k j} / U C F_{j} / I R E_{k j}\right)$ is the water footprint intensity per calorie content considering the irrigation efficiency related to $\triangle \mathrm{F} 6 \_\mathrm{CB}$.

$W B I^{C B}{ }_{0 i}$ is calculated as follows:

$$
\begin{gathered}
W B I^{C B}{ }_{0 i}=\frac{1}{T R W R_{0}} \times \frac{T W W_{0}}{A W W_{0}} \times W R^{C B} \\
W R^{C B}=\sum_{k}^{N_{i j k}} \sum_{j}^{N_{i j}}\left(C O M^{C A L_{0}} \times \frac{C O M^{C A L_{0 j}}}{C O M^{C A L_{0}}} \times \frac{C O M^{C A L_{0 j k}}}{C O M^{C A L_{0 j}}} \times \frac{W F I_{0 j}}{U C F_{j} \times I R E_{0 j}}\right),
\end{gathered}
$$

where $T R W R_{0}, A W W_{0}$, and $T W W_{0}$ are calculated in the same manner as in the aforementioned $W B I^{P B}$ simulation. $C O M^{C A L}{ }_{0}$ is the standard value of calorie-based consumption and calculated by adding the calorie-based consumption for all countries by the global population. $C O M^{C A L}{ }_{0 j}$ and $C O M^{C A L}{ }_{0 j k}$ are the standard values of the calorie-based consumption of item $j$ and that of item $j$ for consuming country $k$, respectively. The former is calculated by adding the calorie-based consumption of item $j$ for all countries by the global population, whereas the latter is calculated by that of item $j$ for producing country $k$. Here, the error of $\triangle F 1 \_C B$ is calculated in the same way as in the aforementioned $W B I^{P B}$ simulation. The global population of $\triangle F 4 \_C B$ or $\triangle F 5 \_C B$ is equal to that of $\triangle F 3 \_C B$. Finally, nearly $70 \%$ of all $W B I^{C B}{ }_{0 i}$ exist at $0.086 \pm 0.0015$.

\subsubsection{Complete Decomposition Analysis}

In this study, the MLI method [14,15] is applied to both the $W B I^{P B}$ and $W B I^{C B}$ to consider the residual terms for calculating contribution factors. If the factors of positive change and those of negative change are simultaneously mixed in an interaction term, the interaction term is attributed to only the former term related to them. If an interaction term consists of factors of positive or negative change not simultaneously mixed with each other, the interaction term is attributed to their related factors.

In the case of the $W B I^{C B}$, first, the MLI method is applied to $\triangle W R^{C B}{ }_{i j k}=W R^{C B}{ }_{i j k}$ $-W R^{C B}{ }_{0 j k}$. Here, $\Delta W R^{C B}{ }_{i j k}$ is decomposed into four factors $\left(\Delta W R^{C B}{ }_{i j k 1}, \Delta W R^{C B}{ }_{i j k 2}\right.$, $\Delta W R^{C B}{ }_{i j k 3}$, and $\left.\triangle W R^{C B}{ }_{i j k 4}\right)$ and is equal to the sum of these four factors. Thus, $\Delta W R^{C B}{ }_{i j k 1}$ is calculated as follows:

$$
\begin{gathered}
\Delta W R^{C B}{ }_{i j k 1}=\Delta x_{1} x_{02} x_{03} x_{04}+\frac{a_{1}}{a_{1}+a_{2}} \Delta x_{1} \Delta x_{2} x_{03} x_{04}+\frac{a_{1}}{a_{1}+a_{3}} \Delta x_{1} x_{02} \Delta x_{3} x_{04} \\
+\frac{a_{1}}{a_{1}+a_{4}} \Delta x_{1} x_{02} x_{03} \Delta x_{4}+\frac{a_{1}}{a_{1}+a_{2}+a_{3}} \Delta x_{1} \Delta x_{2} \Delta x_{3} x_{04}+\frac{a_{1}}{a_{1}+a_{2}+a_{4}} \Delta x_{1} \Delta x_{2} x_{03} \Delta x_{4} \\
+\frac{a_{1}}{a_{1}+a_{3}+a_{4}} \Delta x_{1} x_{02} \Delta x_{3} \Delta x_{4}+\frac{a_{1}}{a_{1}+a_{2}+a_{3}+a_{4}} \Delta x_{1} \Delta x_{2} \Delta x_{3} \Delta x_{4} .
\end{gathered}
$$

Here, $\Delta x_{m}$ and $a_{m}$ are defined as follows:

$$
\begin{gathered}
\Delta x_{m}=x_{m}-x_{0 m} \quad(m=1,2,3,4) \\
a_{m}=\frac{\Delta x_{m}}{\frac{x_{m}+x_{0 m}}{2}}(m=1,2,3,4),
\end{gathered}
$$

where $x_{m}$ is the $m$ th factor for the consuming country, item, and producing country (omitted respective subscripts $i, j$, and $k$ ), and $x_{0 m}$ is the standard value of the $m$ th factor. The value of $a_{m}$ with $\Delta x_{m}<0$ is set to zero as long as the total number of $a_{m}$ with an allocation coefficient of $\Delta x_{m}<0$ is less than that of the denominator of the allocation factor. If all of the variables of $\Delta x_{m}$ are negative values, each allocation coefficient is replaced with the difference between one and itself, and $a_{m}$ with $\Delta x_{m}<0$ is not set to zero. For example, 
allocation coefficients $\left\{a_{1} /\left(a_{1}+a_{2}\right)\right\},\left\{a_{1} /\left(a_{1}+a_{2}+a_{3}\right)\right\}$, and $\left\{a_{1} /\left(a_{1}+a_{2}+a_{3}+a_{4}\right)\right\}$ are replaced with $\left\{1-a_{1} /\left(a_{1}+a_{2}\right)\right\},\left\{1-(1 / 2) \times a_{1} /\left(a_{1}+a_{2}+a_{3}\right)\right\}$, and $\left\{1-(1 / 3) \times a_{1} /\left(a_{1}\right.\right.$ $\left.\left.+a_{2}+a_{3}+a_{4}\right)\right\}$, respectively. The same is true for $\Delta W R^{C B}{ }_{i j k 2}$ to $\Delta W R^{C B}{ }_{i j k 4}$. It should be noted that each substitution formula of weight coefficients with over three $a_{m}$ is uniquely formulated by referring to the literature [14,15].

Second, $\triangle W B I^{C B}{ }_{i j k}$ is decomposed into three factors $\left(\triangle W B I^{C B}{ }_{i j k 1}, \triangle W B I^{C B}{ }_{i j k 2}\right.$, and $\triangle W B I^{C B}{ }_{i j k W R} ; \triangle W B I^{C B}{ }_{i j k W R}$ is a water requirement factor) as follows:

$$
\begin{gathered}
\Delta W B I^{C B}{ }_{i j k 1}=\Delta y_{1} y_{02} y_{0 W R}+\frac{b_{1}}{b_{1}+b_{2}} \Delta y_{1} \Delta y_{2} y_{0 W R}+\frac{b_{1}}{b_{1}+b_{W R}} \Delta y_{1} y_{02} \Delta y_{W R}+\frac{b_{1}}{b_{1}+b_{2}+b_{W R}} \Delta y_{1} \Delta y_{2} \Delta y_{W R} \\
\Delta W B I^{C B}{ }_{i j k 2}=y_{01} \Delta y_{2} y_{0 W R}+\frac{b_{2}}{b_{1}+b_{2}} \Delta y_{1} \Delta y_{2} y_{0 W R}+\frac{b_{2}}{b_{2}+b_{W R}} y_{01} \Delta y_{2} \Delta y_{W R}+\frac{b_{2}}{b_{1}+b_{2}+b_{W R}} \Delta y_{1} \Delta y_{2} \Delta y_{W R} \\
\Delta W B I^{C B}{ }_{i j k W R}=y_{01} y_{02} \Delta y_{W R}+\frac{b_{W R}}{b_{1}+b_{W R}} \Delta y_{1} y_{02} \Delta y_{W R}+\frac{b_{W R}}{b_{2}+b_{W R}} y_{01} \Delta y_{2} \Delta y_{W R}+\frac{b_{W R}}{b_{1}+b_{2}+b_{W R}} \Delta y_{1} \Delta y_{2} \Delta y_{W R} .
\end{gathered}
$$

Here, $\Delta y_{n}$ and $b_{n}$ are defined as follows:

$$
\begin{aligned}
\Delta y_{n} & =y_{n}-y_{0 n} \quad(n=1,2, W R) \\
b_{n} & =\frac{\Delta y_{n}}{\frac{y_{n}+y_{0 n}}{2}}(n=1,2, W R),
\end{aligned}
$$

where $y_{n}$ is the $n$th factor $(n=1,2)$ or factor of the $W R^{C B}(n=W R)$ for the consuming country, item, and producing country (omitted respective subscripts $i, j$, and $k$ ). $y_{0 n}$ is the standard value of the $n$th factor $(n=1,2)$ or factor of the $W R^{C B}(n=W R)$. Each $b_{n}$ is calculated in the same way as in the aforementioned description. If all $\Delta y_{n}$ are negative values, each allocation coefficient is replaced with the difference between one and itself, and $b_{n}$ when $\Delta y_{n}<0$ is not set to zero. In Equation (21), allocation coefficients $\left\{b_{1} /\left(b_{1}+b_{2}\right)\right\}$, $\left\{b_{1} /\left(b_{1}+b_{W R}\right)\right\}$, and $\left\{b_{1} /\left(b_{1}+b_{2}+b_{W R}\right)\right\}$ are replaced with $\left\{1-b_{1} /\left(b_{1}+b_{2}\right)\right\},\left\{1-b_{1} /\left(b_{1}\right.\right.$ $\left.\left.+b_{W R}\right)\right\}$, and $\left\{1-(1 / 2) \times b_{1} /\left(b_{1}+b_{2}+b_{W R}\right)\right\}$, respectively. It should be noted that each substitution formula of weight coefficients composed of three $b_{n}$ is uniquely formulated by referring to the literature $[14,15]$.

Finally, substituting $\triangle W R^{C B}{ }_{i j k}$ for $\Delta y_{W R}$ enables $\triangle W B I^{C B}{ }_{i j k}$ to be decomposed into six factors (from $\triangle \mathrm{F} 1 \_\mathrm{CB}$ to $\triangle \mathrm{F} 6 \_\mathrm{CB}$ ) by rearranging each term of Equations (21)-(23) to satisfy Equation (13).

In the case of the $W B I^{P B}, \triangle W B I^{P B}{ }_{i j k}$ is decomposed into five factors (from $\triangle \mathrm{F} 1 \_\mathrm{PB}$ to $\triangle F 5 \_P B$ ) by changing from Equation (18) with four factors to an equation with three factors (the same form as Equation (21)) regarding $\triangle W B I^{P B}{ }_{i j k 1}$. The same is true for $\triangle W B I^{P B}{ }_{i j k 2}$ and $\triangle W B I^{P B}{ }_{i j k 3}$.

For both the $W B I^{P B}$ and $W B I^{C B}$, the total number of samples is different for each country. The total numbers of samples for the $W B I^{P B}$ and $W B I^{C B}$ are shown in Tables $A 1$ and $A 2$ (Appendix A), respectively. In other words, some of the samples are excluded from the decomposition analysis targets when either their numerators or denominators are equal to zero.

\subsection{Study Target and Usage Data}

In this study, the target year is set to 2010 to use simulation data of import and export quantities obtained from our previous study [15]. In addition, 175 countries and 78 food items are targeted by referring to the commodity balance sheets of the FAOSTAT [31,32]. Only mainland China is embodied as China, and Hong Kong SAR, Macao SAR, and Taiwan Province are handled as trade partner countries. For the water supply-demand balances and decomposition analysis, 156 countries are targeted. Two countries (Maldives and Saint Vincent and the Grenadines) are excluded from both analyses because their $A W W^{\prime}$ 's are zero, and therefore, their $W B I^{P B}$ and $W B I^{C B}$ values diverge to positive infinity. In addition, 
17 countries are excluded due to the lack of data on any of the TRWR's, $A W W^{\prime}$, and TWW's. However, these 19 countries only include the trade partner total of 156 nations.

For the food supply-demand balances, the production and domestic supply quantities for each country and item refer to the commodity balance table of the FAOSTAT [31,32]. The import and export quantities for each country and item refer to the commodity balance sheets [31,32] and the detailed trade matrix of the FAOSTAT [33]. For the $W R^{P B}$ and $W R^{C B}$, the water footprint intensity and irrigation efficiency for each country and item are the literature values $\left([28,29]\right.$, respectively). For both the $W B I^{P B}$ and $W B I^{C B}$, the TRWR's, $A W W$, and TWW for each country refer to AQUASTAT [34]. For the decomposition analysis, the calorie conversion factor mainly refers to the Standard Tables of Food Composition in Japan in the reference year [35], and missing data are replaced with that the data of 2015 [36]. The calorie conversion factors for items applied to the median refer to several statistical databases [35-38] and the literature value [39]. The amount of distribution by cuts of meat refers to the statistical data [40]. Population data are obtained from the demographic data of the FAOSTAT [41].

\section{Results}

\subsection{Comparing Production-Based and Consumption-Based Water Balance Indices}

As shown in Figure 1a, 58 countries from the moderate to very high intensity regions based on the $W B I^{P B}$ tend to be distributed around the mid-latitude regions, such as arid regions, large population regions, and industrialized countries. In contrast, Figure $1 \mathrm{~b}$ shows that 72 countries from the moderate to very high intensity regions based on the $W B I^{C B}$ tend to be concentrated in Northern Europe, Africa, Central Asia, Western Asia, and several island countries around Africa and the Caribbean region.

A comparison of the intensities between the $W B I^{P B}$ and $W B I^{C B}$ shows that the former is higher for 17 countries, whereas the latter is higher for 36 countries. In addition, 103 countries are approximately the same, including 40 countries from the moderate to very high intensity regions. For example, China's $W B I^{P B}$ is 0.49 and $W B I^{C B}$ is 0.38 , and the United States of America's $W B I^{P B}$ is 0.20 and $W B I^{C B}$ 0.096. The intensities of the $W B I^{P B}$ can increase because of food production for export. In contrast, the United Kingdom has a $W B I^{P B}$ of 0.16 and $W B I^{C B}$ of 0.61 , and South Africa has a $W B I^{P B}$ of 0.29 and $W B I^{C B}$ of 0.43 . The intensities of the $W B I^{C B}$ tend to rise due to their food trade, and they can increase the water balance intensities of producing countries through their food imports.

\subsection{Comparing Decomposition of Production-Based and Consumption-Based Water Balance Indices}

Figure $2 \mathrm{a}-\mathrm{c}$ shows the number of countries based on the five promoting factors and five offset factors of the $W B I^{P B}$. There are 98 countries in the very low or low intensity regions, 16 countries in the moderate intensity region, and 42 countries in the high or very high intensity regions. In the very low or low intensity regions, $\triangle F 1$ PB is the major promoting factor for 31 countries, followed by $\triangle \mathrm{F} 2 \_\mathrm{PB}$ for 30 countries, and $\Delta \mathrm{F} 4 \_\mathrm{PB}$ for 19 countries. In the moderate-intensity region, $\Delta \mathrm{F} 1 \_\mathrm{PB}$ and $\Delta \mathrm{F} 2 \_\mathrm{PB}$ are tied for six countries and are relatively large promoting factors, followed by $\triangle F 4 \_P B$ and $\Delta F 5 \_P B$ for two countries in a tie. In the high or very high intensity regions, 20 countries have $\Delta F 1 \_P B$ as the major promoting factor, followed by $\triangle \mathrm{F} 5 \_\mathrm{PB}$ for ten countries, and $\triangle \mathrm{F} 2 \_\mathrm{PB}$ and $\triangle \mathrm{F} 4 \_\mathrm{PB}$ for five countries in a tie. 


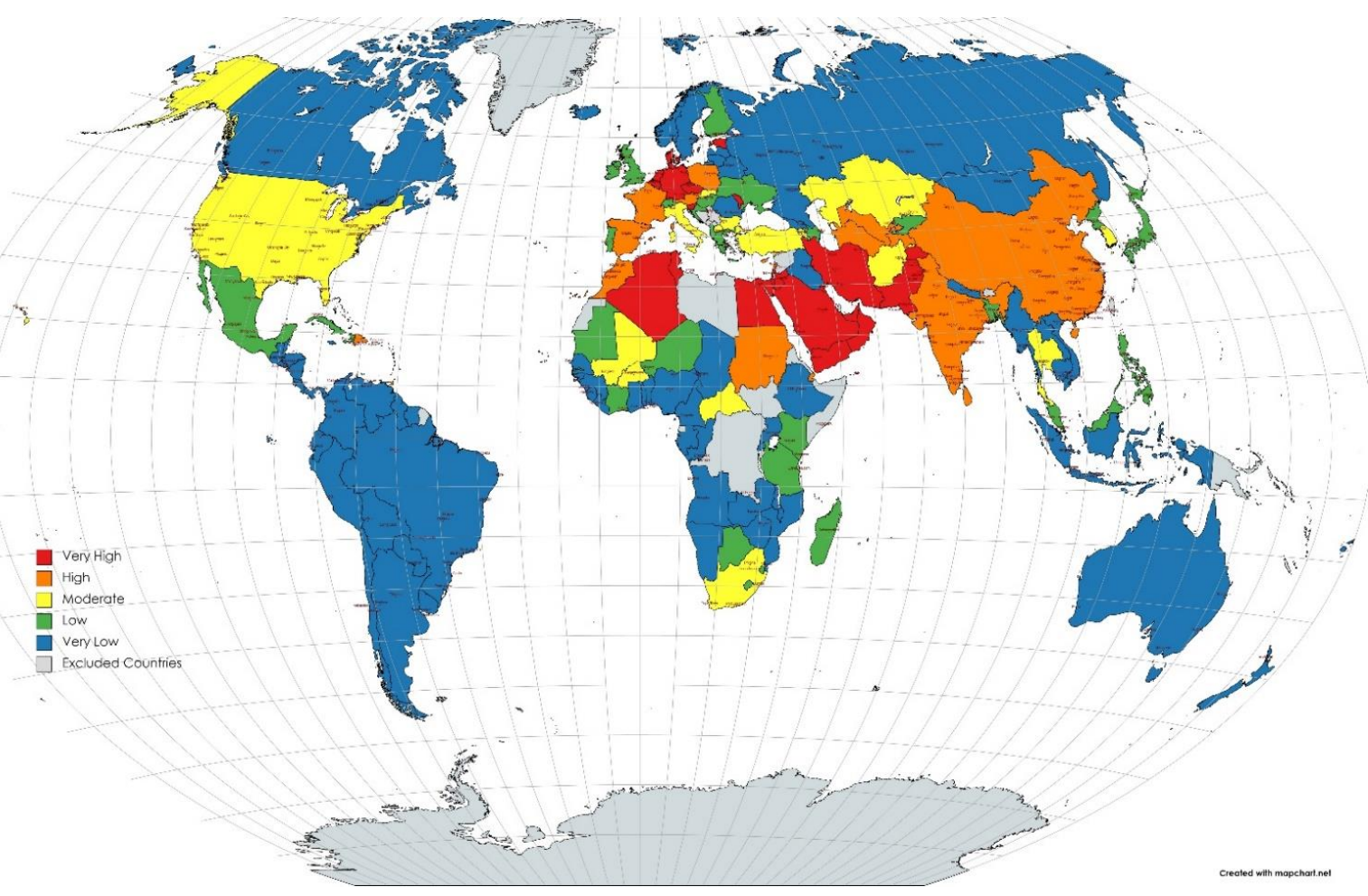

(a)

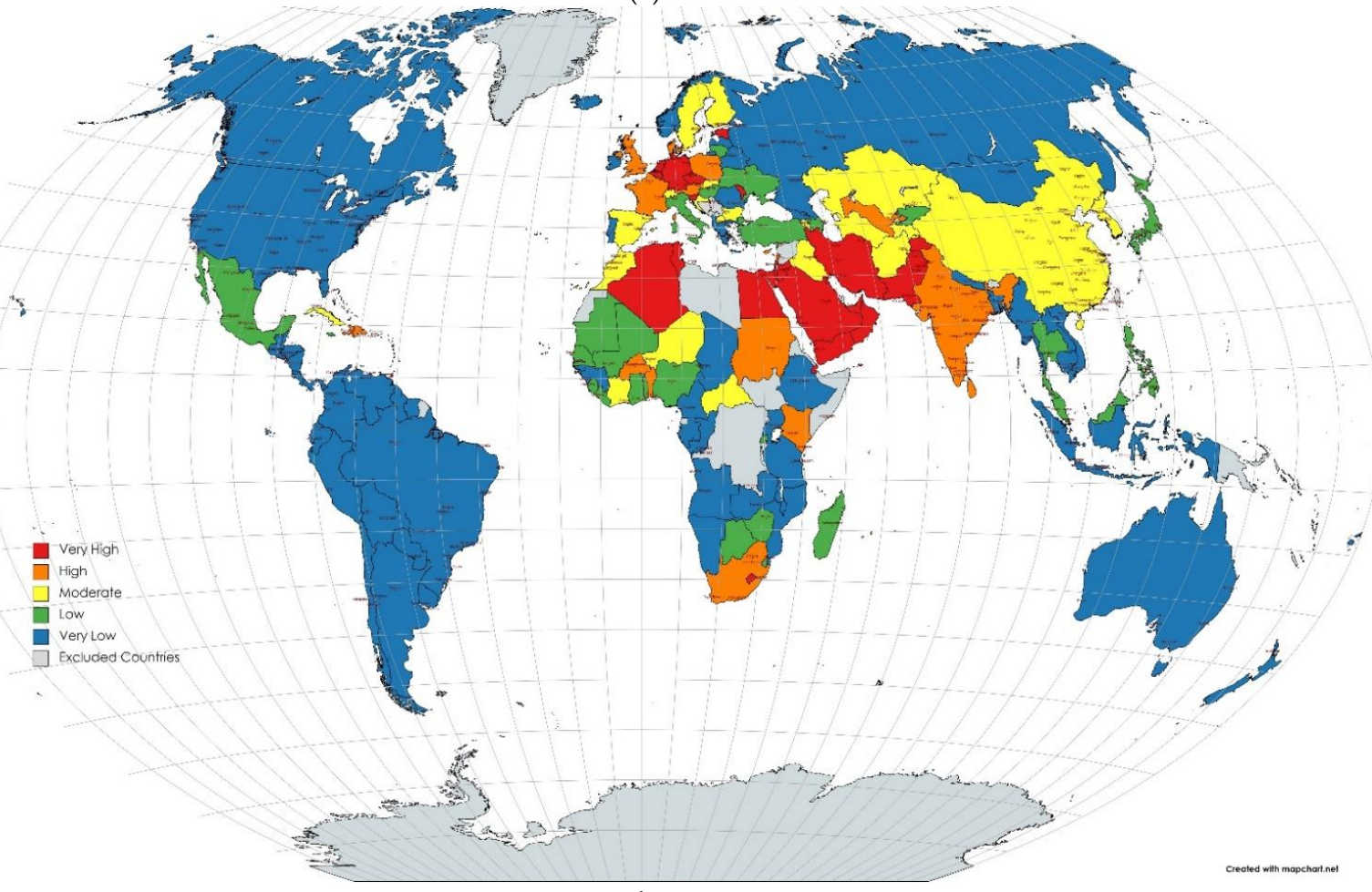

(b)

Figure 1. Global distribution map for two water balance indices: (a) $W B I^{P B}$; (b) $W B I^{C B}$. Note: $W B I^{P B}$ is the production-based water balance index, and $W B I^{C B}$ is the consumption-based water balance index. Each color represents as follows: "Red": very high intensity, "Orange": high intensity, "Yellow": moderate intensity, "Green": low intensity, "Blue": very low intensity, and "Gray" is excluded countries from both $W B I^{P B}$ and $W B I^{C B}$ analyses. 


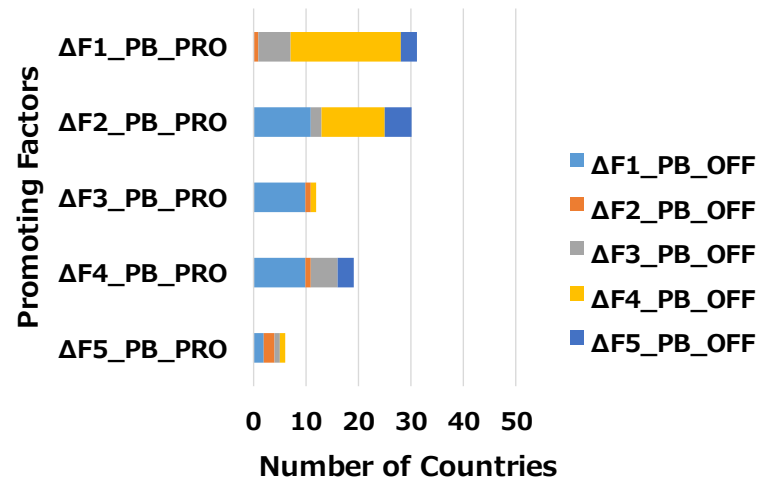

Very low or low intensity regions (a)

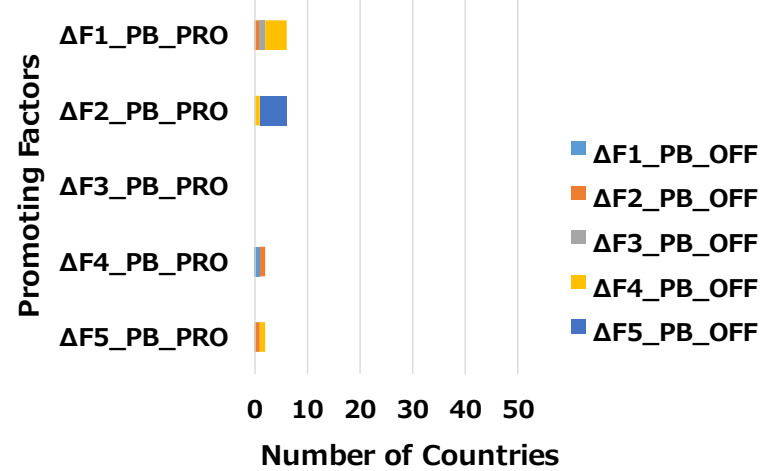

Moderate intensity region (b)

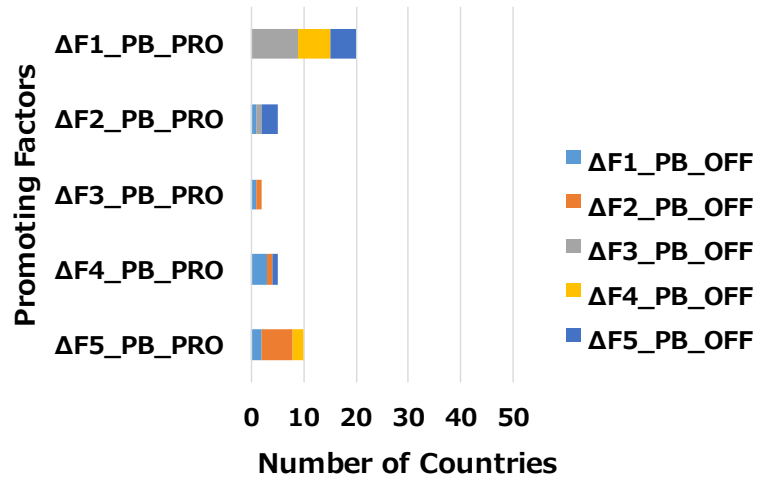

High or very high intensity regions (c)

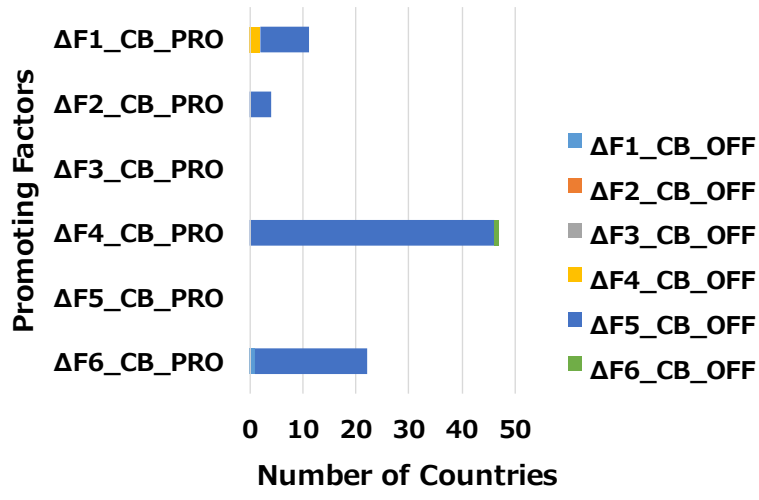

Very low or low intensity regions (d)

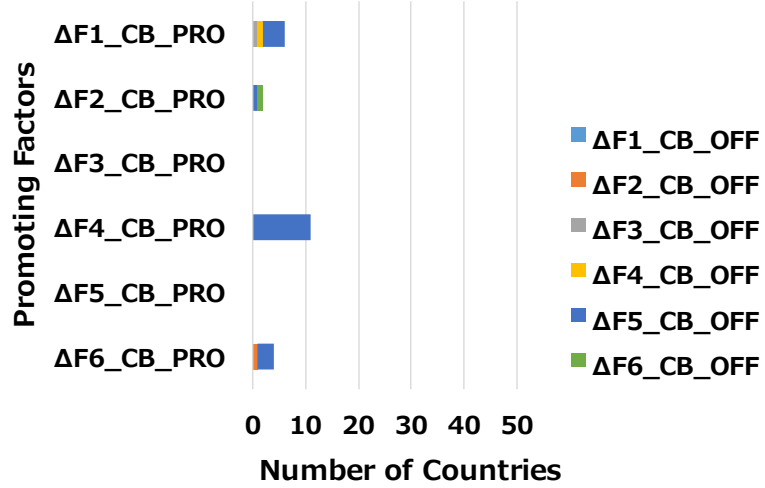

Moderate intensity region (e)

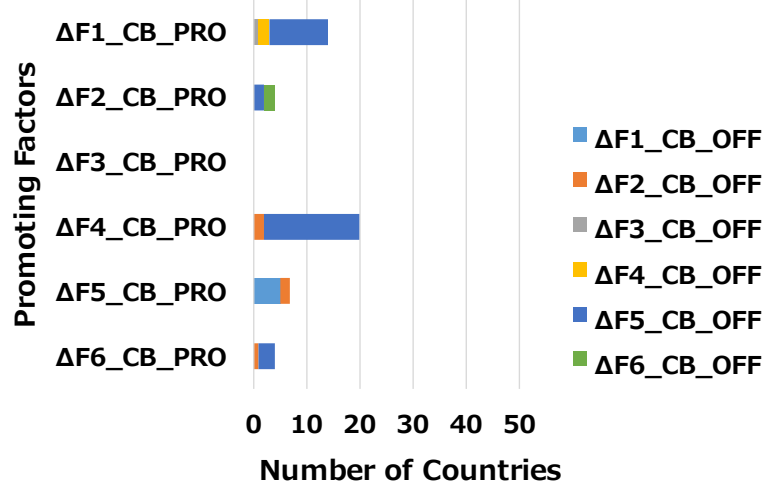

High or very high intensity regions (f)

Figure 2. Number of countries based on (a-c) five promoting factors and five offset factors of $W B I^{P B}$, and (d-f) six promoting factors and six offset factors of $W B I^{C B}:(\mathbf{a}, \mathbf{d})$ in the very low or low intensity regions; $(\mathbf{b}, \mathbf{e})$ in the moderate intensity region; and $(\mathbf{c}, \mathbf{f})$ in the high or very high intensity regions. Note: Five factors for $W B I^{P B}$ are defined as follows: $\triangle F 1 \_P B$ is the renewable freshwater resources factor, $\triangle \mathrm{F} 2 \_\mathrm{PB}$ is the industrial structure factor, $\triangle \mathrm{F} 3 \_\mathrm{PB}$ is the production scale factor, $\triangle F 4 \_P B$ is the produced item preference factor, and $\triangle F 5$ PB is the water footprint intensity factor. Six factor for WBICB are defined as follows: $\triangle F 1$ is the consumption scale factor, $\triangle F$ 4_CB is the consumed item preference factor, $\triangle F 5$ FB is the producing area preference factor, and $\triangle \mathrm{F} 6 \_\mathrm{CB}$ is the water footprint intensity factor. Each factor of $W B I^{P B}$ (from $\triangle \mathrm{F} 1 \_\mathrm{PB}$ to $\triangle \mathrm{F} 5 \_\mathrm{PB}$ ) and of $W B I^{C B}$ (from $\triangle \mathrm{F} 1 \_\mathrm{CB}$ to $\triangle \mathrm{F} 6 \_\mathrm{CB}$ ) is aggregated by the summation of item $j$ for each country and for each $n$. Vertical axis shows five (from $\triangle \mathrm{F} 1 \_\mathrm{PB} \_\mathrm{PRO}$ to $\triangle \mathrm{F} 5$ _PB_PRO for $W B I^{P B}$ ) or six (from $\triangle \mathrm{F} 1 \_\mathrm{CB} \_\mathrm{PRO}$ to $\triangle \mathrm{F} 6 \_\mathrm{CB} \_\mathrm{PRO}$ for $W B I^{C B}$ ) promoting factors. Explanatory note shows five (from $\triangle \mathrm{F} 1 \_\mathrm{PB} \_\mathrm{OFF}$ to $\triangle \mathrm{F} 5 \_\mathrm{PB} \_\mathrm{OFF}$ for $W B I^{P B}$ ) or six (from $\triangle \mathrm{F} 1 \_\mathrm{CB} \_\mathrm{OFF}$ to $\Delta \mathrm{F} 6 \_\mathrm{CB} \_\mathrm{OFF}$ for $W B I^{C B}$ ) offset factors. 
Focusing on offset factors for $W B I^{P B}, \triangle \mathrm{F} 4 \_\mathrm{PB}$ is the major offset factor for 35 countries in the very low or low intensity regions, followed by $\triangle \mathrm{F} 1 \_\mathrm{PB}$ for 33 countries, and $\Delta \mathrm{F} 3 \_\mathrm{PB}$ for 14 countries. In the moderate-intensity region, six countries have $\triangle \mathrm{F} 4 \_\mathrm{PB}$ as the major offset factor, followed by $\triangle \mathrm{F} 5 \_\mathrm{PB}$ for five countries, and $\triangle \mathrm{F} 2 \_\mathrm{PB}$ for the three countries. In the high or very high intensity regions, ten countries have $\triangle \mathrm{F} 3 \_\mathrm{PB}$ as the major offset factors, followed by $\Delta \mathrm{F} 5 \_\mathrm{PB}$ for nine countries, and $\Delta \mathrm{F} 2 \_\mathrm{PB}$ and $\Delta \mathrm{F} 4 \_\mathrm{PB}$ for eight countries in a tie.

Figure $2 \mathrm{~d}-\mathrm{f}$ shows the number of countries based on the six promoting factors and six offset factors of the $W B I^{C B}$. There are 84 countries in the very low or low intensity regions, 23 countries in the moderate intensity region, and 49 countries in the high or very high intensity regions. In the very low or low intensity regions, $\triangle \mathrm{F} 4 \_\mathrm{CB}$ is the major promoting factor for 47 countries, followed by $\triangle \mathrm{F} 6 \_\mathrm{CB}$ for 22 countries, and $\triangle \mathrm{F} 1 \_\mathrm{CB}$ for 11 countries. In the moderate-intensity region, $\triangle \mathrm{F} 4 \_\mathrm{CB}$ is the major promoting factor for 11 countries, followed by $\triangle \mathrm{F} 1 \_\mathrm{CB}$ for six countries, and $\triangle \mathrm{F} 6 \_\mathrm{CB}$ for four countries. In the high or very high intensity regions, $\triangle \mathrm{F} 4 \_\mathrm{CB}$ is the major promoting factor for 20 countries, followed by $\triangle \mathrm{F} 1 \_\mathrm{CB}$ for 14 countries, and $\triangle \mathrm{F} 5 \_\mathrm{CB}$ for seven countries.

Focusing on offset factors for $W B I^{C B}$ in the very low or low intensity regions, $\triangle \mathrm{F} 5$ _CB is the major promoting factor for 80 countries, followed by $\triangle \mathrm{F} 4$-CB for two countries, and $\triangle \mathrm{F} 1 \_\mathrm{CB}$ and $\triangle \mathrm{F} 6 \_\mathrm{CB}$ being equal for one country. In the moderate-intensity region, $\triangle \mathrm{F} 5 \_\mathrm{CB}$ is the major offset factor for 19 countries, followed by $\triangle \mathrm{F} 2 \_\mathrm{CB}, \triangle \mathrm{F} 3 \_\mathrm{CB}, \triangle \mathrm{F} 4{ }_{-} \mathrm{CB}$, and $\triangle \mathrm{F} 6$ _CB being equal for one country. In the high or very high intensity regions, $\triangle \mathrm{F} 5 \_C B$ is the major offset factor for 34 countries, followed by $\Delta \mathrm{F} 1 \_\mathrm{CB}$ and $\Delta \mathrm{F} 2 \_\mathrm{CB}$ for five countries in a tie, and $\triangle \mathrm{F} 4 \_\mathrm{CB}$ and $\triangle \mathrm{F} 6 \_\mathrm{CB}$ for two countries in a tie.

In summary, based on $W B I^{P B}$, the renewable freshwater resources factor $\left(\triangle \mathrm{F} 1 \_\mathrm{PB}\right)$ becomes the major promoting factor in the very low, low-, and high or very high-intensity regions while $\triangle \mathrm{F} 1 \_\mathrm{PB}$ and $\triangle \mathrm{F} 2 \_\mathrm{PB}$ are relatively large promoting factors in the moderateintensity region. The $W B I^{P B}$ is constrained by renewable freshwater resources and industrial structures rather than food production. The major offset factor for $W B I^{P B}$ is $\triangle \mathrm{F} 4 \_\mathrm{PB}$ for countries in the very low-to moderate-intensity regions. The high or very high intensity regions have $\triangle \mathrm{F} 3 \_\mathrm{PB}$ as the major offset factor for $W B I^{P B}$. Changing high-calorie food into low-calorie food production is expected to lead to a decrease in the intensities of $W B I^{P B}$. On the other hand, based on $W B I^{C B}$, the consumed item preference factor $(\triangle \mathrm{F} 4 \mathrm{CB})$ becomes the major promoting factor for all regions. The major offset factor for $W B I^{C B}$ is the producing area preference $\left(\triangle \mathrm{F} 5 \_\mathrm{CB}\right)$ for all regions. Although high-calorie food consumption increases the intensities of $W B I^{C B}$, food imports from regions with lower water requirements decrease those of $W B I^{C B}$. The intensities of $W B I^{P B}$ and $W B I^{C B}$ are determined by the balance of the degrees of contribution between the promoting and offset factors.

For example, China belongs to the high or very high intensity regions based on the $W B I^{P B}$. As shown in Table A1, the major promoting factor is the renewable freshwater resources factor $\left(\triangle \mathrm{F} 1 \_\mathrm{PB} \_\mathrm{PRO}\right.$ : 0.44$)$, which is mainly offset by the water footprint intensity factor $\left(\triangle \mathrm{F} 5 \_P B \_O F F:-6.8 \times 10^{-2}\right)$. Here, $\Delta \mathrm{F} 1 \_P B \_P R O$ shows that $\triangle F 1 \_P B$ is a promoting factor (a positive value), whereas $\triangle \mathrm{F} 5 \_\mathrm{PB} \_\mathrm{OFF}$ shows that $\triangle \mathrm{F} 1 \_\mathrm{PB}$ is an offset factor (a negative value). The respective interpretation rules are the same as below. This shows that the promoting effect on renewable water resources is offset by the production of items with relatively low water requirements per calorie content. This country is a high-intensity region of $W B I^{P B}$ according to Figure $1 \mathrm{a}$; this is determined by adding $\triangle \mathrm{F} 1 \_\mathrm{PB}$ to $\triangle \mathrm{F} 5 \_\mathrm{PB}$ depending on the balance of degrees of contribution between the three promoting and two offset factors (Table A1). In contrast, this country belongs to the moderate-intensity region based on $W B I^{C B}$. As shown in Table A2, the major promoting factor is the water footprint intensity factor ( $\left.\triangle \mathrm{F} 6 \_C B \_P R O: 3.4\right)$, which is mainly offset by the producing area preference factor $\left(\triangle \mathrm{F} 5 \_\mathrm{CB}\right.$ _OFF: -3.4$)$. This shows that the promoting effect on food production with high water requirements per calorie content is offset by food imports from regions with lower water requirements. China is a moderate-intensity region of $W B I^{C B}$ according to Figure $1 \mathrm{~b}$; this is determined by adding $\triangle \mathrm{F} 1 \_\mathrm{CB}$ to $\triangle \mathrm{F} 6 \_\mathrm{CB}$ depending on the balance of 
degrees of contribution between the four promoting and two offset factors (Table A2). In summary, the water balance intensity of $W B I^{P B}$ in China mainly increases because of the renewable freshwater resources factor and is mainly offset by the water footprint intensity factor. On the other hand, the intensities of $W B I^{C B}$ mainly increase because of the producing area preference factor and is offset by the producing area preference factor.

As another example, the United States of America belongs to the moderate-intensity region based on their $W B I^{P B}$. As shown in Table A1, the major promoting factor is the industrial structure factor $\left(\triangle \mathrm{F} 2 \_\mathrm{PB} \_\mathrm{PRO}: 8.5 \times 10^{-2}\right)$, which is mainly offset by the water footprint intensity $\left(\triangle \mathrm{F} 5\right.$ _PB_OFF: $\left.-3.0 \times 10^{-2}\right)$. This occurs because the $A W W$ per capita ( $282 \mathrm{~m}^{3} /$ capita) is less than the $I W W$ per capita $\left(101 \mathrm{~m}^{3} /\right.$ capita). This effect is mainly offset by the consumption of items with relatively low water requirements per calorie content. The United States of America is a moderate-intensity region of $W B I^{P B}$ according to Figure 1a, which is determined by adding $\triangle \mathrm{F} 1 \_\mathrm{PB}$ to $\triangle \mathrm{F} 5$ _PB depending on the balance of degrees of contribution between the two promoting and three offset factors (Table A1). In contrast, this country belongs to the very low or low intensity regions based on their $W B I^{C B}$. As shown in Table A2, the major promoting factor is the producing item preference factor $\left(\triangle F 4 \_C B \_P R O\right.$ : $0.66)$, which is mainly offset by the water footprint intensity factor ( $\triangle \mathrm{F} 5$ _CB_OFF: -0.87 ). This shows that the effect of high-calorie content on food consumption is offset by the effect on food imports from regions with lower water requirements. This country is a moderate-intensity region of $W B I^{C B}$ according to Figure $1 \mathrm{~b}$, which is determined by adding $\triangle \mathrm{F} 1 \_\mathrm{CB}$ to $\triangle \mathrm{F} 6 \_\mathrm{CB}$ depending on the balance of degrees of contribution between the two promoting and four offset factors (Table A2). In summary, the intensities of $W B I^{P B}$ in the United States of America mainly increase owing to the industrial structure factor and are mainly offset by the water footprint intensity factor. On the other hand, the intensities of $W B I^{C B}$ mainly increase because of the consumed item preference factor and are mainly offset by the producing area preference factor.

\section{Discussion}

In 2010, the TRWR per capita is $8036 \mathrm{~m}^{3} /$ capita, the $A W W$ per capita is $406 \mathrm{~m}^{3} /$ capita, and the TWW per capita is $583 \mathrm{~m}^{3} /$ capita, on a global average. The respective values correspond to $T R W R_{0}, A W W_{0}$, and $T W W_{0}$, those are used in Equations (11) and (16). The ration of $A W W_{0}$ to $T W W_{0}$ shows that global $A W W$ accounts for approximately $70 \%$ of global $T W W$. Agricultural water demand is prominent and in danger of increasing water balance intensities.

According to Figure 3, rice has a prominent blue water requirement on global average. Its blue water footprint intensity is $5350 \mathrm{~m}^{3} /$ ton with $356 \mathrm{kcal} / 100 \mathrm{~g}$ of calorie content, the minimum value in all of the items, considering its irrigation efficiency is 0.1. For cereals, maize has the largest share of global calorie-based production ( $44 \%$ of cereals) and requires $155 \mathrm{~m}^{3} /$ ton of blue water. Wheat follows by $33 \%$ and $656 \mathrm{~m}^{3} /$ ton, showing the largest blue water intensity in all cereals, and $6.8 \%$ and $152 \mathrm{~m}^{3} /$ ton for barley. The respective calorie content are $350 \mathrm{kcal} / 100 \mathrm{~g}$ for maize, $337 \mathrm{kcal} / 100 \mathrm{~g}$ for wheat, and $341 \mathrm{kcal} / 100 \mathrm{~g}$ for barley. For oil crops and oils, olive oil has the largest blue water intensity, requiring $4677 \mathrm{~m}^{3} /$ ton of blue water with $921 \mathrm{kcal} / 100 \mathrm{~g}$ of calorie content. However, its share of global calorie-based production is $0.77 \%$ for oil crops and oils, which is less than that for palm oil ( $11 \%$ of oil crops and oils), followed by $10 \%$ for coconuts, $9.5 \%$ for soybean oil, $8.2 \%$ for rape and mustard seeds, and $5.7 \%$ for cottonseed. The respective blue water intensities are $2 \mathrm{~m}^{3} /$ ton with $921 \mathrm{kcal} / 100 \mathrm{~g}$ of calorie content for palm oil, $4 \mathrm{~m}^{3} /$ ton with $668 \mathrm{kcal} / 100 \mathrm{~g}$ for coconuts, $263 \mathrm{~m}^{3} /$ ton with $921 \mathrm{kcal} / 100 \mathrm{~g}$ for soybean oil, $328 \mathrm{~m}^{3} /$ ton with $500 \mathrm{kcal} / 100 \mathrm{~g}$ for rape and mustard seeds, and $802 \mathrm{~m}^{3} /$ ton with $506 \mathrm{kcal} / 100 \mathrm{~g}$ for cottonseed. Soybeans have the largest share of global calorie-based production ( $27 \%$ of oil crops and oils) of all the oil crops and oils. Its blue water intensity is $134 \mathrm{~m}^{3} /$ ton with $417 \mathrm{kcal} / 100 \mathrm{~g}$ of calorie content. For livestock products, "Meat, Other" (already integrating relatively minor meat items except for bovine, pig, poultry, mutton, and goat meat and edible offal in the FAOSTAT) has the largest blue water intensity $\left(1223 \mathrm{~m}^{3} / \mathrm{ton}\right)$ with $119 \mathrm{kcal} / 100 \mathrm{~g}$ of calorie 
content. However, its share of global calorie-based production takes the minimum value in all livestock products at only $0.41 \%$. Milk has the largest share of global calorie-based production ( $28 \%$ of livestock products) in all of the livestock products, followed by $18 \%$ for pig meat, and $14 \%$ for bovine meat. The respective blue water intensities are $165 \mathrm{~m}^{3} /$ ton with $66 \mathrm{kcal} / 100 \mathrm{~g}$ of calorie content for milk, $622 \mathrm{~m}^{3} /$ ton with $294 \mathrm{kcal} / 100 \mathrm{~g}$ for pig meat, and $1044 \mathrm{~m}^{3} /$ ton with $360 \mathrm{kcal} / 100 \mathrm{~g}$ for bovine meat. Poultry meat's share of global calorie-based production is $11 \%$, requiring $601 \mathrm{~m}^{3} /$ ton of blue water with $194 \mathrm{kcal} / 100 \mathrm{~g}$ of calorie content. It seems that global blue water requirements mainly increase due to the large production of rice and relatively high water-required items with a large share of global calorie-based production rather than because of items with the largest blue water requirement in each item category. In particular, the blue water requirement for producing oil crops and oils increases due to the production of oil crops rather than oils.

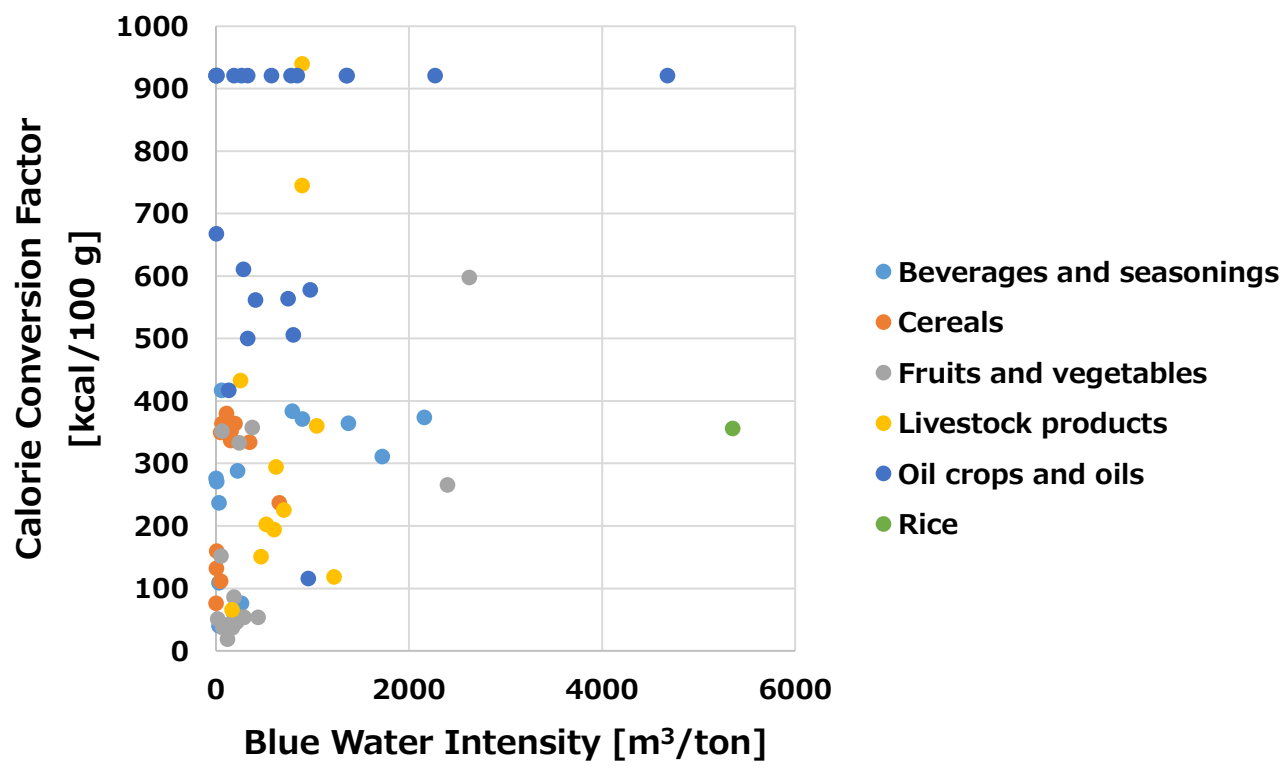

Figure 3. Scatter plot of blue water intensities and calorie conversion factors for six item categories. Note: The target items (78 items) are aggregated in six categories as follows: "Cereals" for 13 items, "Beverages and seasonings" for 13 items, "Fruits and vegetables" for 18 items, "Oil crops and oils" for 22 items, "Livestock products" for 11 items, and "Rice" for one items. The blue water intensity means blue water footprint intensity considering irrigation efficiency on a world average.

The scatter plot in Figure 4a shows a clearly symmetric distribution centered around four on the horizontal axis. There are 98 countries in the very low or low intensity regions, 16 countries in the moderate intensity region, and 42 countries in the high or very high intensity regions. Countries in the very low or low intensity regions have a wide spread ranging from $10^{3}$ to $10^{8}$. Counties in the high or very high regions spread in the range of 10 to $10^{4}$. Countries with moderate intensity have a spread between $10^{3}$ to $10^{4}$. In the very low or low intensity regions, the largest calorie-based production quantity per capita is $48 \mathrm{GJ} /$ capita in Argentina, followed by $40 \mathrm{GJ} /$ capita in Canada, and $39 \mathrm{GJ} /$ capita in Paraguay. In the moderate-intensity region, the largest calorie-based production quantity per capita is $31 \mathrm{GJ} /$ capita in the United States of America, followed by $22 \mathrm{GJ} /$ capita in Bulgaria and Kazakhstan, and 14 GJ/capita in Slovakia and Thailand. In the high or very high intensity regions, the largest calorie-based production quantity per capita is 40 GJ/capita in Demark, followed by 26 GJ/capita in France, and 18 GJ/capita in the Czech Republic, Poland and Austria. China has calorie-based production quantity per capita of 8.8 GJ/capita. In summary, calorie-based production quantities per capita tend to be higher in the very low or low intensity regions than in the moderate to very high intensity regions. 


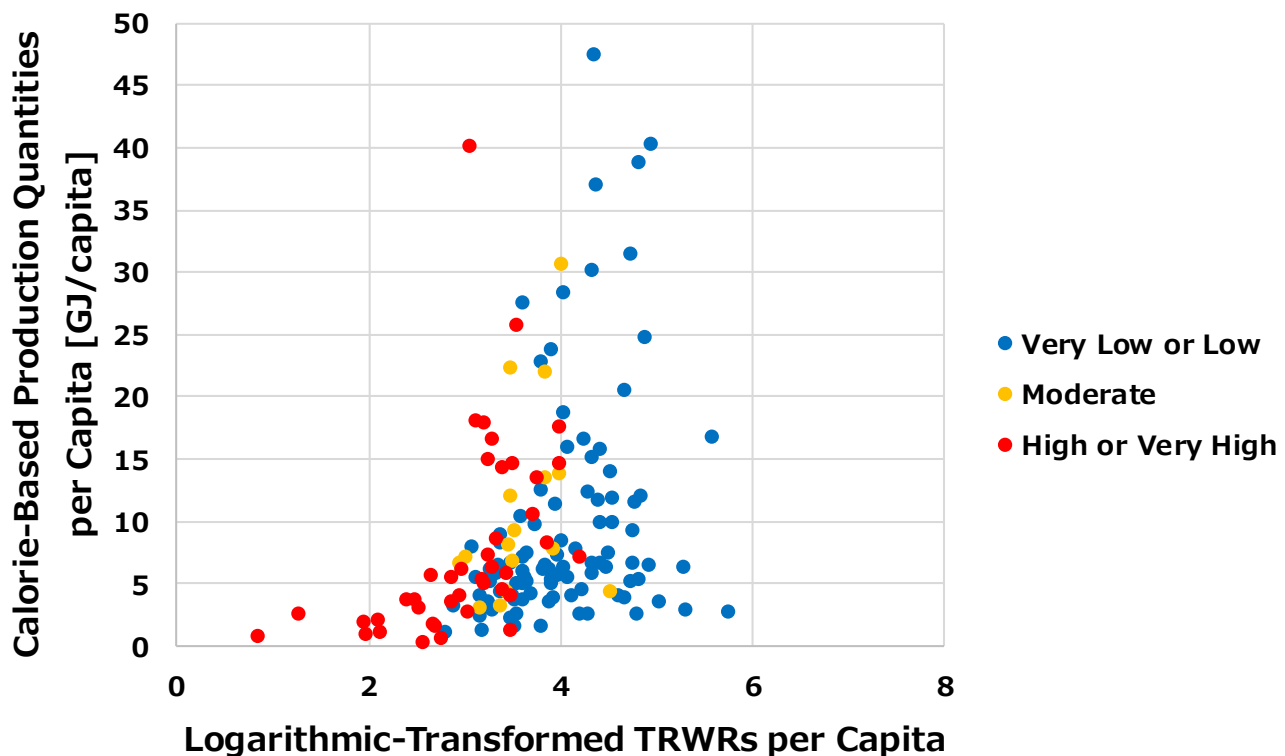

(a)

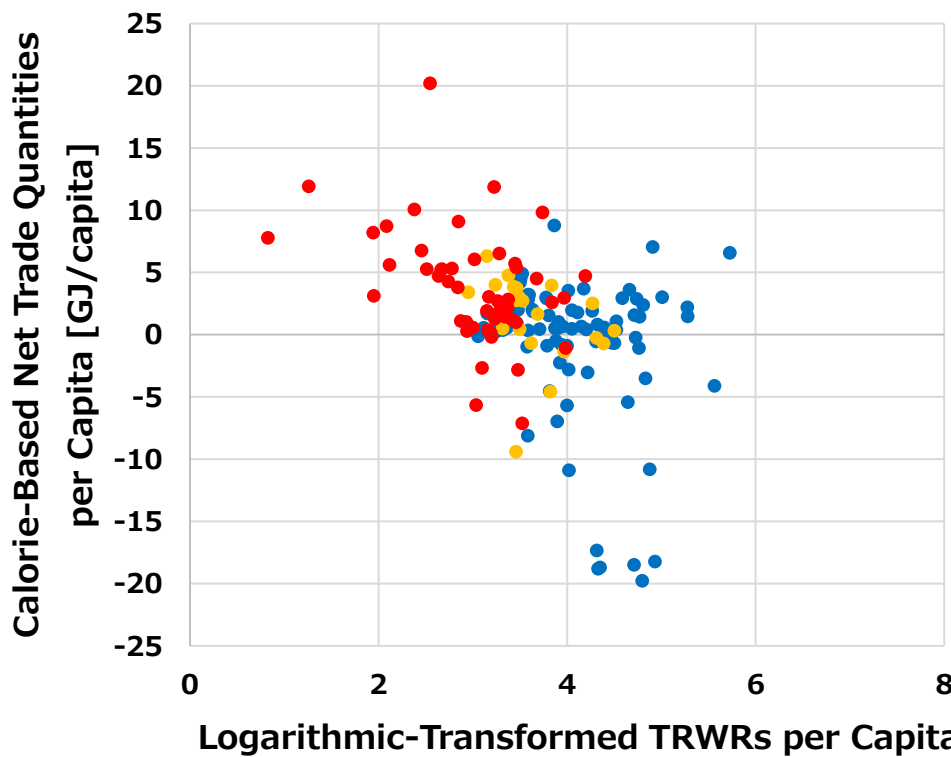

- Very Low or Low

- Moderate

- High or Very High

(b)

Figure 4. (a) Scatter plot of calorie-based production quantities per capita and logarithmictransformed TRWR's per capita for three water balance intensities of $W B I^{P B}$ worldwide. (b) Scatter plot of calorie-based net trade quantities per capita and logarithmic-transformed TRWR's per capita for three water balance intensities of $W B I^{C B}$ worldwide. Note: TRWR's are short for the renewable total water resources.

Figure $4 \mathrm{~b}$ shows that countries in the high or very high intensity regions concentrate on net importers. Globally, net importers are dispersed independently of water balance intensities except for several net exporters of the very low or low intensity regions with prominent calorie-based net export quantities per capita. In the high or very high intensity regions, the number of net importers is 43 , more than that of net exporters (six countries). In the moderate-intensity region, the number of net importers is 17 , more than that of net exporters (six countries). In the very low or low intensity regions, the number of net importers (53 countries) is greater than that of net exporters ( 31 countries). In total, 
113 countries depend on food imports from 43 exporter countries. For example, in the high or very high intensity regions, the largest calorie-based net import quantity per capita is $20 \mathrm{GJ} /$ capita in Djibouti, followed by $12 \mathrm{GJ} /$ capita in the United Arab Emirates and Belgium, and $10 \mathrm{GJ} /$ capita in Israel and The Netherlands. The United States of America has $5.7 \mathrm{GJ} /$ capita of calorie-based net export quantities per capita. The largest calorie-based net export quantity is $7.1 \mathrm{GJ} /$ capita in France, followed by $5.6 \mathrm{GJ} /$ capita in Denmark, and 2.8 GJ/capita in the Republic of Moldova. In the moderate-intensity region, the largest calorie-based net import quantity per capita is $6.3 \mathrm{GJ} /$ capita in the Republic of Korea, followed by $4.8 \mathrm{GJ} /$ capita in Spain, and 4.0 GJ/capita in Saint Lucia and Switzerland. China has $1.1 \mathrm{GJ} /$ capita of calorie-based net import quantities per capita. The largest calorie-based net export quantity per capita is $9.4 \mathrm{GJ} /$ capita in Bulgaria, followed by 4.6 GJ/capita in Kazakhstan, and 1.3 GJ/capita in Slovakia. In the very low or low intensity regions, the largest calorie-based net export quantity per capita is 20 GJ/capita in Paraguay, followed by 19 GJ/capita in Argentina and Australia, and 18 GJ/capita in Uruguay and Canada. The largest calorie-based net import quantity per capita is $8.8 \mathrm{GJ} /$ capita in Portugal, followed by 7.1 GJ/capita in Norway, and 6.6 GJ/capita in Iceland. In summary, most countries are net importers that spread worldwide, whereas food exports are covered by a few net exporters.

Figure $5 \mathrm{a}, \mathrm{b}$ shows that cereals' share of calorie-based production quantities for each intensity of $W B I^{P B}$ is the largest in all of the items. The respective total calorie-based production quantities are $26,000 \mathrm{PJ}\left(0.94 \times 10^{3} \mathrm{~km}^{3}\right)$ in the very low or low intensity regions, $13,000 \mathrm{PJ}\left(0.54 \times 10^{3} \mathrm{~km}^{3}\right)$ in the moderate intensity region, and $27,000 \mathrm{PJ}\left(3.1 \times 10^{3} \mathrm{~km}^{3}\right)$ in the high or very high intensity regions. In the very low or low intensity regions, the largest share of calorie-based production quantities is 35\% (9.3 $\left.\times 10^{3} \mathrm{PJ}\right)$ for cereals, followed by $32 \%\left(8.5 \times 10^{3} \mathrm{PJ}\right)$ for oil crops and oils, $11 \%\left(2.8 \times 10^{3} \mathrm{PJ}\right)$ for rice, and $9.0 \%$ $\left(2.4 \times 10^{3} \mathrm{PJ}\right)$ for livestock products. The respective shares of blue water requirements are $6.5 \%\left(61 \mathrm{~km}^{3}\right)$ for cereals, $1.7 \%\left(16 \mathrm{~km}^{3}\right)$ for oil crops and oils, $69 \%\left(0.65 \times 10^{3} \mathrm{~km}^{3}\right)$ for rice, and $12 \%\left(0.11 \times 10^{3} \mathrm{~km}^{3}\right)$ for livestock products. In the moderate-intensity region, the largest share of calorie-based production quantities is $57 \%\left(7.5 \times 10^{3} \mathrm{PJ}\right)$ for cereals, followed by $21 \%\left(2.7 \times 10^{3} \mathrm{PJ}\right)$ for oil crops and oils, $11 \%\left(1.4 \times 10^{3} \mathrm{PJ}\right)$ for livestock products, and $4.2 \%\left(0.55 \times 10^{3} \mathrm{PJ}\right)$ for rice. The respective shares of blue water requirements are $15 \%\left(80 \mathrm{~km}^{3}\right)$ for cereals, $6.1 \%\left(33 \mathrm{~km}^{3}\right)$ for oil crops and oils, $13 \%\left(71 \mathrm{~km}^{3}\right)$ for livestock products, and $53 \%\left(0.29 \times 10^{3} \mathrm{~km}^{3}\right)$ for rice. In the high or very high intensity regions, the largest share of calorie-based production quantities is $43 \%\left(11 \times 10^{3} \mathrm{PJ}\right)$ for cereals, followed by $18 \%\left(4.8 \times 10^{3} \mathrm{PJ}\right)$ for oil crops and oils, $14 \%\left(3.6 \times 10^{3} \mathrm{PJ}\right)$ for rice, and $12 \%$ $\left(3.2 \times 10^{3} \mathrm{PJ}\right)$ for livestock products. The respective shares of blue water requirements are $22 \%\left(0.67 \times 10^{3} \mathrm{~km}^{3}\right)$ for cereals, $5.3 \%\left(0.16 \times 10^{3} \mathrm{~km}^{3}\right)$ for oil crops and oils, $50 \%$ $\left(1.5 \times 10^{3} \mathrm{~km}^{3}\right)$ for rice, and $11 \%\left(0.33 \times 10^{3} \mathrm{~km}^{3}\right)$ for livestock products. Based on caloriebased production quantities, cereals, rice, livestock products, and oil crops and oils are produced worldwide. However, based on blue water requirements, rice is the most waterintensive item of all because its irrigation efficiency is 0.1 , requiring ten times as many water withdrawals as its blue water consumption. In summary, rice and cereals increase global blue water requirements for production because the respective items have the largest share of blue water requirements and calorie-based production quantities in all of the items for all of the regions. 


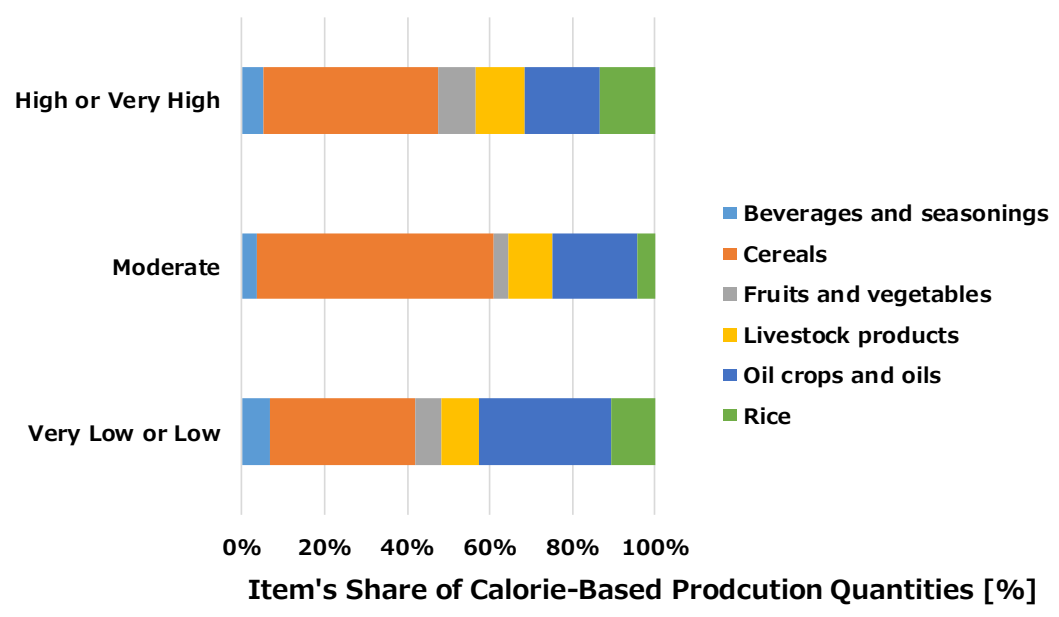

(a)

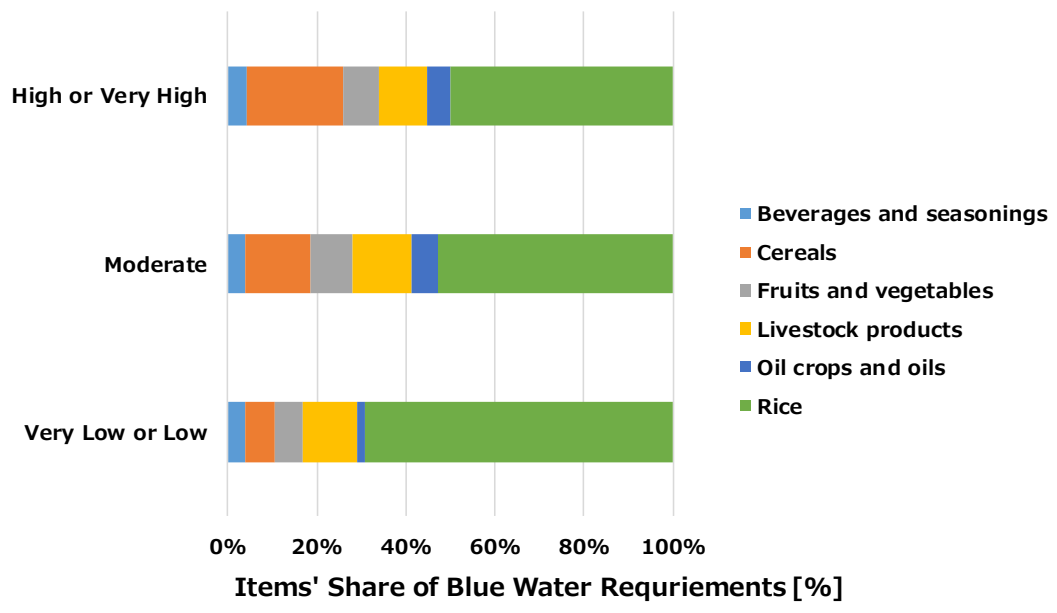

(b)

Figure 5. (a) Items' share of calorie-based production quantities and (b) item's share of blue water requirements for production for three water balance intensities of $W B I^{P B}$. Note: The target items (78 items) are aggregated in the same six categories as Figure 3.

Figure $6 \mathrm{a}, \mathrm{b}$ depict that the very low and low intensity regions show a net exporter on both bases, whereas the moderate-intensity region shows a net importer. The high or very high intensity regions show a net exporter on a calorie basis in contrast with a net importer region on a blue water requirement basis. In the very low or low intensity regions, the total calorie-based net export quantity is $4.6 \times 10^{3} \mathrm{PJ}$, and the total net export quantity of blue water requirements is $11 \mathrm{~km}^{3}$ with no net import quantities on both bases. In the moderate-intensity region, the total calorie-based net import quantity is $2.2 \times 10^{3} \mathrm{PJ}$, and the total net import quantity of blue water requirements is $35 \mathrm{~km}^{3}$. The total calorie-based net export quantity is $22 \mathrm{PJ}$ with no net export quantities of blue water requirements. In the high or very high intensity regions, the total calorie-based net import quantity is $1.9 \times 10^{3} \mathrm{PJ}$, and the total net import quantity of blue water requirements is $0.38 \mathrm{~km}^{3}$. Meanwhile, the total calorie-based net export quantity is $56 \mathrm{PJ}$, and the total net export quantity of blue water requirements is $21 \mathrm{~km}^{3}$. Based on blue water requirements, rice is largely exported to Western Africa $\left(24 \mathrm{~km}^{3}\right.$ and $\left.16 \mathrm{PJ}\right)$, followed by Western Asia ( $23 \mathrm{~km}^{3}$ and $31 \mathrm{PJ})$, and Eastern Africa $\left(23 \mathrm{~km}^{3}\right.$ and $\left.11 \mathrm{PJ}\right)$. These are offset by rice imports from Southern Asia $\left(43 \mathrm{~km}^{3}\right.$ and $\left.36 \mathrm{PJ}\right)$, followed by South-Eastern Asia $\left(11 \mathrm{~km}^{3}\right.$ and $\left.42 \mathrm{PJ}\right)$, and North America $\left(6.8 \mathrm{~km}^{3}\right.$ and $\left.8.1 \mathrm{PJ}\right)$. Four items (e.g., rice, cereals, livestock products, and oil crops and oils) in particular show net importers on a calorie basis, in contrast with 
showing net exporters on a blue water requirement basis. This contrast could be caused by the stacked difference of blue water requirements because the blue water intensity for each item is different between producing countries. The calorie conversion factor for each item is constant and not separately set among producing countries. In summary, oil crops and oils have the largest share of calorie-based net trade worldwide. However, blue water requirements for oil crops and oils are less than those for rice and as much as those of cereals. Thus, rice trade increases global blue water requirements.

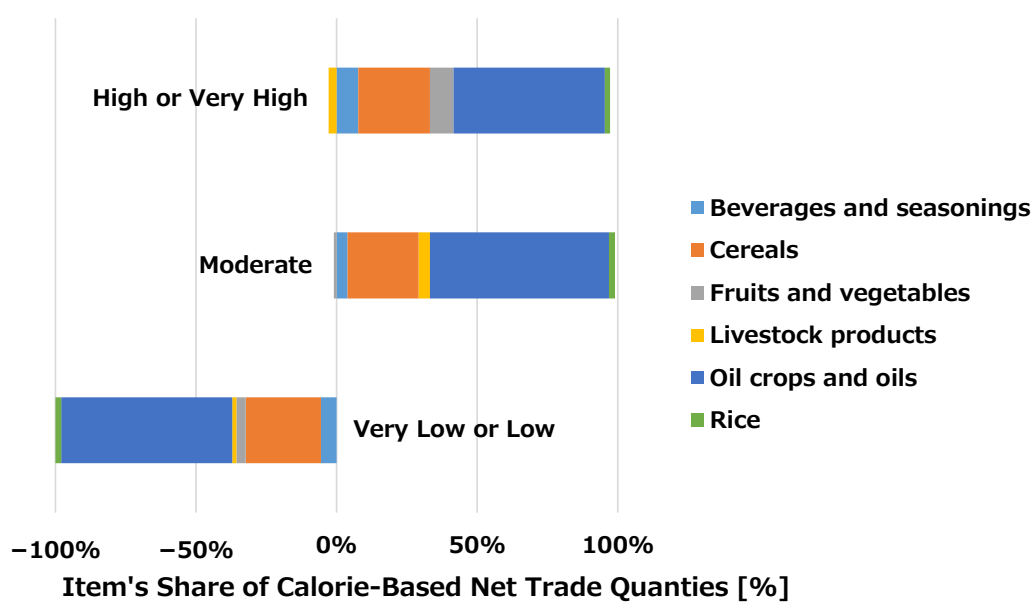

(a)

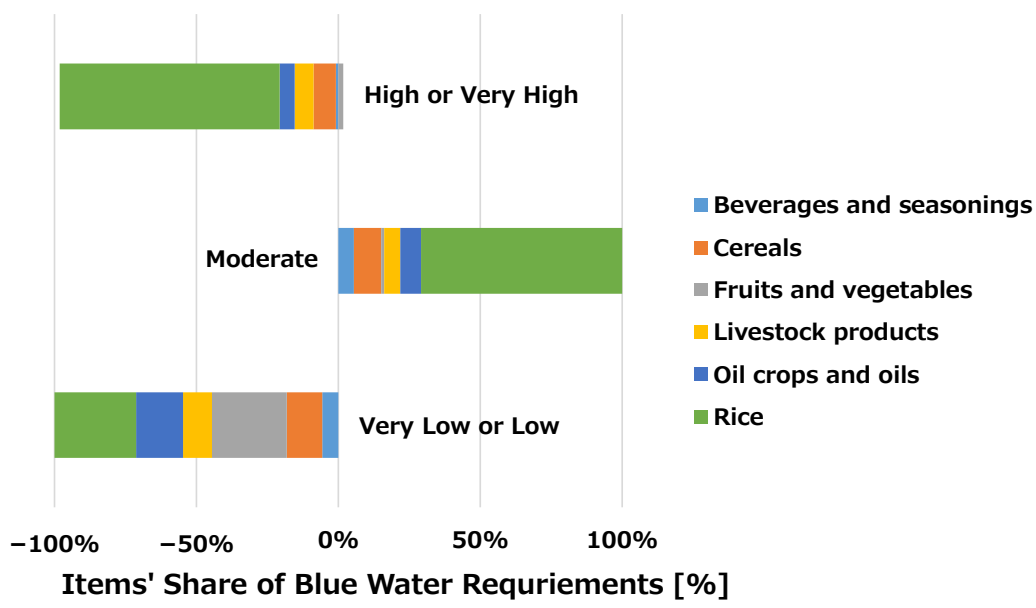

(b)

Figure 6. (a) Items' share of calorie-based net trade quantities and (b) items' share of net trade quantities of blue water requirements for three water balance intensities of $W B I^{C B}$. Note: The target items (78 items) are aggregated in the same six categories as Figure 3.

\section{Conclusions}

This study aims to evaluate the intensities of water supply-demand balances (water balance intensities) and elucidate the promoting factors of water balance intensities (promoting factors) or offset factors of water balance intensities (offset factors) for each country, focusing on food supply-demand balances and considering food trade balances on a global scale. A complete decomposition analysis is applied to both the $W B I^{P B}$ and the $W B I^{C B}$ to analyze the promoting and offset factors of both WBI's. The $W B I^{P B}$ is decomposed into five factors as follows: a renewable freshwater resources factor, an industrial structure factor, a production scale factor, a produced item preference factor, and a water footprint intensity factor. The $W B I^{C B}$ is decomposed into six factors as follows: a renewable freshwater resources factor, an industrial structure factor, a consumption scale factor, a consumed item 
preference factor, a producing area preference factor, and a water footprint intensity factor. The elucidation of the promoting and offset factors of both WBIs is expected to provide essential knowledge for decreasing water balance intensities regarding food production and consumption based on water resource management. In this study, the following three results are revealed:

(1) The water balance intensity for each country is evaluated using five intensity categories: very low, low, moderate, high, and very high. 58 countries from moderate to very high intensity regions on a $W B I^{P B}$ basis tend to be distributed around midlatitude regions including arid regions, large population regions, and industrialized countries. In contrast, 72 countries from moderate to very high intensity regions on a $W B I^{C B}$ basis are spread worldwide. Comparing intensities between $W B I^{P B}$ and $W B I^{C B}$, the former is higher for 17 countries, whereas the latter is higher for 36 countries. In addition, 103 countries are approximately the same, including 40 countries from moderate to very high regions.

(2) Each country is classified into one of three regions: the very low or low intensity region, the moderate intensity region, and the high or very high intensity region. Based on $W B I^{P B}$, the renewable freshwater resources factor is the major promoting factor in the very low or low and the high or very high intensity regions, while the renewable freshwater resources and industrial structure factors are relatively large promoting factors in the moderate-intensity region. The major offset factor of $W B I^{P B}$ is the consumed item preference factor for countries in the very low to moderate-intensity regions. The high or very high intensity regions have the production scale factor as the major offset factor of the $W B I^{P B}$. Based on $W B I^{C B}$, the consumed item preference factor is the major promoting factor for countries from the very low to moderate regions, and the renewable freshwater resources factor is the major promoting factor for countries in the high or very high intensity regions. In contrast, the major offset factor of $W B I^{C B}$ is the producing area preference for all regions. The water balance intensities of $W B I^{P B}$ and $W B I^{C B}$ are determined to balance the degrees of contribution between the promoting and offset factors.

(3) This study reviews two countries (China and the United States of America) in more detail. In China, the renewable freshwater resources factor is mainly offset by the water footprint intensity factor based on $W B I^{P B}$. In contrast, the water footprint intensity factor is mainly offset by the producing area preference factor based on $W B I^{C B}$. In the United States of America, the water balance intensity of $W B I^{P B}$ mainly increases because of the industrial structure factor, which is offset by the water footprint intensity factor. In contrast, the water balance intensity of $W B I^{C B}$ increases because of the consumed item preference factor, which is offset by the producing area preference factor.

A discussion focusing on food production and trade is provided. Calorie-based production quantities tend to be higher for countries in the very low or low intensity regions than for those in the moderate to very high regions. Most countries are net importers that spread worldwide, whereas food exports are covered by a few net exporters. Rice and cereals increase global blue water requirements for production because the respective items have the largest share of blue water requirements and calorie-based production quantities in all of the items for all of the regions. Oil crops and oils have the largest share of caloriebased net trade worldwide. However, blue water requirements for oil crops and oils are less than those for rice and as much as those for cereal. Thus, rice trade increases global blue water requirements. It is effective to improve irrigation efficiency for rice and cereals because rice has the largest blue water footprint intensity considering irrigation efficiency in all of the items, whereas cereals show the largest share of calorie-based production quantities in all of the items for all of the regions.

Several problems need to be addressed in future studies. This study in particular analyzes water balance intensities, focusing on the elucidation of a global distribution tendency of degrees of promoting and offset factors for each country. Therefore, this 
study could not refer to the relationship between countries in detail. For this reason, more detailed analyses at the regional or country level are necessary. In addition, the standard value of this study differs for each country to apply the complete decomposition analysis to spatial data. The standard value for each factor, the renewable freshwater resources, industrial structure, production (for $W B I^{P B}$ ), and consumption scale (for $W B I^{C B}$ ) factors are set by using world average values per capita while the water footprint intensity factor is set by using the world average values. In contrast, the produced and consumed item preferences (for $W B I^{P B}$ and $W B I^{C B}$, respectively) and producing area preference (for only $W B I^{C B}$ ) factors are set by using distinct values for each country. Additional analyses from various points of view are necessary. Using time series data as degrees of contribution factors can easily change depending on the method of taking standard values and selecting parameters and indices.

This study quantifies water balance intensities based on macroeconomic statistics, such as FAOSTAT and AQUASTAT when calculating food supply-demand factors (food production, consumption, and net trade) and water-related factors (total renewable water resources, agricultural withdrawal rate, and water footprint intensity) to evaluate the effect of these factors on water balance intensities. Therefore, this study could not consider accelerating changes in water footprint, such as various irrigation technology, cultivation methods, and agricultural activities. In addition, green water is excluded from the evaluation target of this study. However, green water could become an indirect effect on water balance intensities because decreasing the availability of green water causes additional blue water use. Additional analysis is necessary to develop this study for the future. For example, creating a new decomposition formula for water requirements incorporating the ratio of virtual water to real water and that for food production incorporating crop yield could adopt appropriate policies to conserve water resources and increase crop productivity, respectively. In addition, analyzing the value of virtual water enables to evaluate the effect of trade dependence between countries on water balance intensities, and therefore, could add economic viewpoint to this study.

It should be noted that this study is based on the FAOSTAT, and therefore the quality of all results of this study highly rely on the data limitation and drawbacks of this statistics. This study could not consider the input-output balances between raw materials and processed goods because the FAOSTAT does not refer to the relationship between two. In addition, this study could not cover unreported data of the FAOSTAT. This statistics' quality depends on the quality of received data, supplied by national statistical authorities or by other international organizations [42]. In future work, the analysis combined with input-output tables is desirable.

Author Contributions: Conceptualization, Y.Y., N.Y., K.A. and S.H.; methodology, Y.Y., N.Y., K.A. and S.H.; software, Y.Y.; validation, Y.Y., N.Y., K.A. and S.H.; formal analysis, Y.Y.; investigation, Y.Y.; resources, N.Y.; data curation, Y.Y., N.Y., K.A. and S.H.; writing-original draft preparation, Y.Y.; writing-review \& editing, Y.Y., N.Y., K.A. and S.H.; visualization, Y.Y., N.Y., K.A. and S.H.; supervision, K.A.; project administration, K.A.; funding acquisition, K.A. and N.Y. All authors have read and agreed to the published version of the manuscript.

Funding: This research was partially supported by the Program for the Strategic Research Foundation at Private Universities, Ministry of Education, Culture, Sports, Science and Technology (MEXT) Japan (S1411032).

Institutional Review Board Statement: Not applicable.

Informed Consent Statement: Not applicable.

Data Availability Statement: Not applicable.

Conflicts of Interest: The authors declare no conflict of interest. 


\section{Appendix A}

Table A1. Decomposition results of $W B I^{P B}$ (unit: \%).

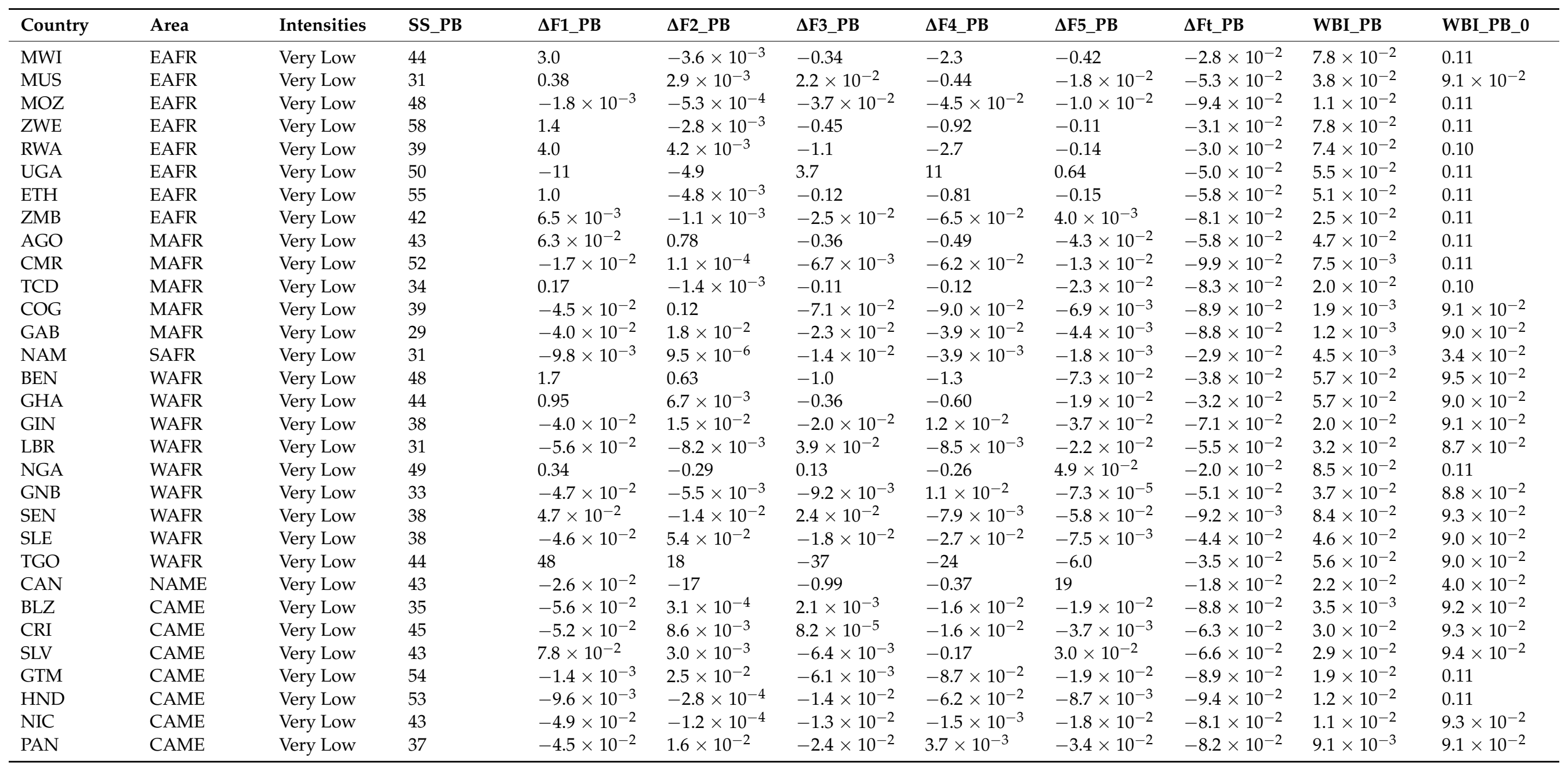


Table A1. Cont.

\begin{tabular}{|c|c|c|c|c|c|c|c|c|c|c|c|}
\hline Country & Area & Intensities & SS_PB & $\Delta \mathrm{F} 1 \_\mathrm{PB}$ & $\Delta \mathrm{F} 2 \_\mathrm{PB}$ & $\Delta$ F3_PB & $\Delta \mathrm{F} 4 \_\mathrm{PB}$ & $\Delta$ F5_PB & $\Delta \mathrm{Ft} \_\mathrm{PB}$ & WBI_PB & WBI_PB_0 \\
\hline JAM & CARI & Very Low & 39 & 0.19 & $4.0 \times 10^{-2}$ & $-4.6 \times 10^{-2}$ & -0.22 & $-1.6 \times 10^{-2}$ & $-5.4 \times 10^{-2}$ & $3.7 \times 10^{-2}$ & $9.1 \times 10^{-2}$ \\
\hline LCA & CARI & Very Low & 28 & 0.19 & $-9.5 \times 10^{-5}$ & $-5.6 \times 10^{-2}$ & -0.12 & $-9.6 \times 10^{-3}$ & $7.2 \times 10^{-3}$ & $2.3 \times 10^{-2}$ & $1.6 \times 10^{-2}$ \\
\hline ARG & SAME & Very Low & 60 & $-5.2 \times 10^{-2}$ & $-6.9 \times 10^{-4}$ & $3.1 \times 10^{-2}$ & $-4.7 \times 10^{-2}$ & $-1.0 \times 10^{-2}$ & $-8.0 \times 10^{-2}$ & $3.1 \times 10^{-2}$ & 0.11 \\
\hline BRA & SAME & Very Low & 65 & $-7.4 \times 10^{-2}$ & $3.7 \times 10^{-3}$ & $1.2 \times 10^{-2}$ & $-2.6 \times 10^{-2}$ & $-1.2 \times 10^{-2}$ & $-9.6 \times 10^{-2}$ & $1.4 \times 10^{-2}$ & 0.11 \\
\hline $\mathrm{CHL}$ & SAME & Very Low & 48 & $-6.8 \times 10^{-2}$ & $5.4 \times 10^{-4}$ & $-5.2 \times 10^{-3}$ & $-2.8 \times 10^{-2}$ & $5.7 \times 10^{-3}$ & $-9.5 \times 10^{-2}$ & $1.2 \times 10^{-2}$ & 0.11 \\
\hline COL & SAME & Very Low & 58 & $-6.9 \times 10^{-2}$ & $5.4 \times 10^{-3}$ & $-1.9 \times 10^{-2}$ & $-1.1 \times 10^{-2}$ & $-8.0 \times 10^{-3}$ & -0.10 & $8.8 \times 10^{-3}$ & 0.11 \\
\hline ECU & SAME & Very Low & 59 & $-6.9 \times 10^{-2}$ & $-3.9 \times 10^{-3}$ & $-4.3 \times 10^{-3}$ & $-1.0 \times 10^{-3}$ & $1.8 \times 10^{-3}$ & $-7.6 \times 10^{-2}$ & $3.1 \times 10^{-2}$ & 0.11 \\
\hline PRY & SAME & Very Low & 51 & $-7.7 \times 10^{-2}$ & $-1.2 \times 10^{-4}$ & $1.0 \times 10^{-2}$ & $-1.9 \times 10^{-2}$ & $-1.3 \times 10^{-2}$ & -0.10 & $8.1 \times 10^{-3}$ & 0.11 \\
\hline PER & SAME & Very Low & 62 & $-8.4 \times 10^{-2}$ & $-3.5 \times 10^{-3}$ & $-6.2 \times 10^{-3}$ & $-7.0 \times 10^{-4}$ & $-9.6 \times 10^{-4}$ & $-9.6 \times 10^{-2}$ & $1.4 \times 10^{-2}$ & 0.11 \\
\hline SUR & SAME & Very Low & 36 & $-7.9 \times 10^{-2}$ & $2.4 \times 10^{-5}$ & $-1.7 \times 10^{-3}$ & $6.2 \times 10^{-3}$ & $-1.9 \times 10^{-3}$ & $-7.6 \times 10^{-2}$ & $1.4 \times 10^{-2}$ & $9.0 \times 10^{-2}$ \\
\hline URY & SAME & Very Low & 49 & $-7.7 \times 10^{-2}$ & $-3.0 \times 10^{-3}$ & $3.7 \times 10^{-2}$ & $-1.7 \times 10^{-3}$ & $8.6 \times 10^{-4}$ & $-4.4 \times 10^{-2}$ & $6.3 \times 10^{-2}$ & 0.11 \\
\hline VEN & SAME & Very Low & 54 & $-6.2 \times 10^{-2}$ & $9.6 \times 10^{-4}$ & $-2.8 \times 10^{-2}$ & $-6.3 \times 10^{-3}$ & $-5.0 \times 10^{-3}$ & -0.10 & $6.3 \times 10^{-3}$ & 0.11 \\
\hline MNG & EASI & Very Low & 23 & $-7.4 \times 10^{-3}$ & $2.1 \times 10^{-2}$ & $-1.6 \times 10^{-2}$ & $2.3 \times 10^{-2}$ & $-6.0 \times 10^{-3}$ & $1.5 \times 10^{-2}$ & $4.4 \times 10^{-2}$ & $3.0 \times 10^{-2}$ \\
\hline NPL & SASI & Very Low & 47 & $2.6 \times 10^{-3}$ & $-2.6 \times 10^{-2}$ & $-2.8 \times 10^{-2}$ & $2.5 \times 10^{-2}$ & $1.1 \times 10^{-2}$ & $-1.5 \times 10^{-2}$ & $9.2 \times 10^{-2}$ & 0.11 \\
\hline MMR & SEASI & Very Low & 48 & $-5.7 \times 10^{-2}$ & $-7.7 \times 10^{-3}$ & $2.1 \times 10^{-3}$ & $6.4 \times 10^{-3}$ & $-1.8 \times 10^{-2}$ & $-7.4 \times 10^{-2}$ & $3.2 \times 10^{-2}$ & 0.11 \\
\hline $\mathrm{LAO}$ & SEASI & Very Low & 36 & $-6.8 \times 10^{-2}$ & $-4.2 \times 10^{-3}$ & $-4.1 \times 10^{-4}$ & $5.5 \times 10^{-3}$ & $-8.2 \times 10^{-3}$ & $-7.5 \times 10^{-2}$ & $1.7 \times 10^{-2}$ & $9.2 \times 10^{-2}$ \\
\hline TLS & SEASI & Very Low & 28 & $6.1 \times 10^{-3}$ & $-1.3 \times 10^{-2}$ & $-4.3 \times 10^{-2}$ & $2.6 \times 10^{-2}$ & $-2.1 \times 10^{-2}$ & $-4.5 \times 10^{-2}$ & $4.2 \times 10^{-2}$ & $8.7 \times 10^{-2}$ \\
\hline VNM & SEASI & Very Low & 45 & $-1.3 \times 10^{-2}$ & $-1.9 \times 10^{-2}$ & $-5.5 \times 10^{-3}$ & $6.0 \times 10^{-2}$ & $-2.8 \times 10^{-2}$ & $-4.9 \times 10^{-3}$ & $8.9 \times 10^{-2}$ & $9.4 \times 10^{-2}$ \\
\hline GEO & WASI & Very Low & 40 & $-8.6 \times 10^{-3}$ & $4.4 \times 10^{-3}$ & $-1.8 \times 10^{-2}$ & $5.4 \times 10^{-3}$ & $-6.5 \times 10^{-3}$ & $-2.3 \times 10^{-2}$ & $1.4 \times 10^{-2}$ & $3.7 \times 10^{-2}$ \\
\hline IRQ & WASI & Very Low & 46 & 0.32 & $-3.8 \times 10^{-3}$ & -0.19 & -0.20 & $5.5 \times 10^{-2}$ & $-1.3 \times 10^{-2}$ & $9.4 \times 10^{-2}$ & 0.11 \\
\hline BLR & EEUR & Very Low & 40 & $1.4 \times 10^{-2}$ & 0.10 & $2.6 \times 10^{-2}$ & $-3.5 \times 10^{-3}$ & -0.10 & $3.3 \times 10^{-2}$ & $7.3 \times 10^{-2}$ & $4.0 \times 10^{-2}$ \\
\hline ROU & EEUR & Very Low & 47 & $-8.6 \times 10^{-3}$ & 1.1 & $8.7 \times 10^{-2}$ & -0.85 & -0.32 & $-7.9 \times 10^{-3}$ & 0.10 & 0.11 \\
\hline RUS & EEUR & Very Low & 48 & $-5.4 \times 10^{-2}$ & 0.22 & $9.7 \times 10^{-3}$ & -0.32 & $7.5 \times 10^{-2}$ & $-6.5 \times 10^{-2}$ & $4.3 \times 10^{-2}$ & 0.11 \\
\hline ISL & NEUR & Very Low & 17 & $-1.2 \times 10^{-2}$ & $2.3 \times 10^{-4}$ & $-1.7 \times 10^{-3}$ & $-3.5 \times 10^{-4}$ & $-1.2 \times 10^{-3}$ & $-1.5 \times 10^{-2}$ & $4.0 \times 10^{-4}$ & $1.6 \times 10^{-2}$ \\
\hline LVA & NEUR & Very Low & 36 & $-7.5 \times 10^{-3}$ & -0.18 & $-3.7 \times 10^{-2}$ & 0.35 & -0.14 & $-1.7 \times 10^{-2}$ & $1.6 \times 10^{-2}$ & $3.2 \times 10^{-2}$ \\
\hline LTU & NEUR & Very Low & 38 & $1.2 \times 10^{-3}$ & 0.42 & $-8.6 \times 10^{-3}$ & -0.28 & $-8.8 \times 10^{-2}$ & $4.1 \times 10^{-2}$ & $7.9 \times 10^{-2}$ & $3.8 \times 10^{-2}$ \\
\hline NOR & NEUR & Very Low & 29 & $-1.7 \times 10^{-2}$ & $7.1 \times 10^{-3}$ & $-1.9 \times 10^{-3}$ & $-2.1 \times 10^{-3}$ & $-1.4 \times 10^{-2}$ & $-2.8 \times 10^{-2}$ & $2.1 \times 10^{-3}$ & $3.0 \times 10^{-2}$ \\
\hline SWE & NEUR & Very Low & 35 & $-9.8 \times 10^{-3}$ & 0.14 & $-2.3 \times 10^{-2}$ & 1.2 & -1.3 & $4.2 \times 10^{-2}$ & $7.6 \times 10^{-2}$ & $3.4 \times 10^{-2}$ \\
\hline AUS & AUNZ & Very Low & 61 & $-5.6 \times 10^{-2}$ & $7.6 \times 10^{-3}$ & $3.3 \times 10^{-2}$ & $-4.4 \times 10^{-2}$ & $-1.6 \times 10^{-4}$ & $-6.0 \times 10^{-2}$ & $5.1 \times 10^{-2}$ & 0.11 \\
\hline
\end{tabular}


Table A1. Cont.

\begin{tabular}{|c|c|c|c|c|c|c|c|c|c|c|c|}
\hline Country & Area & Intensities & SS_PB & $\Delta \mathrm{F} 1 \_\mathrm{PB}$ & $\Delta \mathrm{F} 2 \_\mathrm{PB}$ & $\Delta$ F3_PB & $\Delta \mathrm{F} 4 \_\mathrm{PB}$ & $\Delta$ F5_PB & $\Delta \mathrm{Ft} \_\mathrm{PB}$ & WBI_PB & WBI_PB_0 \\
\hline NZL & AUNZ & Very Low & 38 & $-2.3 \times 10^{-2}$ & $5.9 \times 10^{-4}$ & $3.9 \times 10^{-3}$ & $3.7 \times 10^{-3}$ & $-8.1 \times 10^{-3}$ & $-2.3 \times 10^{-2}$ & $1.2 \times 10^{-2}$ & $3.5 \times 10^{-2}$ \\
\hline FJI & MELA & Very Low & 32 & $-3.5 \times 10^{-2}$ & $4.4 \times 10^{-3}$ & $1.1 \times 10^{-3}$ & $-5.0 \times 10^{-2}$ & $-6.4 \times 10^{-3}$ & $-8.7 \times 10^{-2}$ & $3.5 \times 10^{-3}$ & $9.0 \times 10^{-2}$ \\
\hline KEN & EAFR & Low & 59 & 25 & $-4.0 \times 10^{-2}$ & -6.8 & -18 & 0.56 & $5.1 \times 10^{-2}$ & 0.16 & 0.11 \\
\hline TZA & EAFR & Low & 62 & -0.20 & $-1.1 \times 10^{-2}$ & 0.18 & 0.19 & -0.14 & $1.6 \times 10^{-2}$ & 0.12 & 0.11 \\
\hline BWA & SAFR & Low & 29 & $1.5 \times 10^{-2}$ & $2.0 \times 10^{-2}$ & $-2.2 \times 10^{-2}$ & $3.1 \times 10^{-2}$ & $4.8 \times 10^{-2}$ & $9.3 \times 10^{-2}$ & 0.11 & $2.1 \times 10^{-2}$ \\
\hline LSO & SAFR & Low & 22 & -18 & -0.12 & 19 & -0.50 & -0.19 & $9.2 \times 10^{-2}$ & 0.12 & $3.1 \times 10^{-2}$ \\
\hline SWZ & SAFR & Low & 35 & 0.15 & $-7.0 \times 10^{-3}$ & $1.0 \times 10^{-3}$ & $-8.7 \times 10^{-2}$ & $-7.9 \times 10^{-3}$ & $5.1 \times 10^{-2}$ & 0.16 & 0.10 \\
\hline GMB & WAFR & Low & 25 & 0.22 & 0.13 & -0.34 & $-3.3 \times 10^{-2}$ & $4.1 \times 10^{-2}$ & $1.9 \times 10^{-2}$ & 0.11 & $8.7 \times 10^{-2}$ \\
\hline CIV & WAFR & Low & 48 & 0.21 & 0.14 & -0.21 & $-8.0 \times 10^{-2}$ & $-4.0 \times 10^{-2}$ & $2.4 \times 10^{-2}$ & 0.12 & $9.4 \times 10^{-2}$ \\
\hline MRT & WAFR & Low & 26 & $9.6 \times 10^{-2}$ & $-1.4 \times 10^{-2}$ & $-2.3 \times 10^{-2}$ & $-1.9 \times 10^{-2}$ & $2.8 \times 10^{-3}$ & $4.3 \times 10^{-2}$ & 0.14 & $9.6 \times 10^{-2}$ \\
\hline NER & WAFR & Low & 38 & 0.81 & $5.8 \times 10^{-3}$ & $-6.2 \times 10^{-2}$ & -0.77 & $1.5 \times 10^{-2}$ & $-6.6 \times 10^{-4}$ & 0.10 & 0.10 \\
\hline MEX & CAME & Low & 70 & 0.18 & $-3.5 \times 10^{-3}$ & $-2.3 \times 10^{-2}$ & -0.17 & $2.2 \times 10^{-2}$ & $5.6 \times 10^{-3}$ & 0.12 & 0.11 \\
\hline CUB & CARI & Low & 40 & 0.27 & $8.5 \times 10^{-3}$ & -0.12 & $2.0 \times 10^{-2}$ & -0.16 & $1.7 \times 10^{-2}$ & 0.11 & $9.1 \times 10^{-2}$ \\
\hline GRD & CARI & Low & 36 & $-5.2 \times 10^{-2}$ & -1.7 & 1.3 & 0.65 & -0.13 & $9.9 \times 10^{-2}$ & 0.12 & $2.2 \times 10^{-2}$ \\
\hline HTI & CARI & Low & 38 & 0.84 & $-5.8 \times 10^{-3}$ & -0.45 & $3.8 \times 10^{-3}$ & -0.34 & $3.9 \times 10^{-2}$ & 0.13 & $9.2 \times 10^{-2}$ \\
\hline PRK & EASI & Low & 34 & 0.20 & $-6.6 \times 10^{-3}$ & $-8.8 \times 10^{-2}$ & $-1.2 \times 10^{-2}$ & $-1.6 \times 10^{-2}$ & $8.0 \times 10^{-2}$ & 0.18 & 0.10 \\
\hline BGD & SASI & Low & 48 & $-1.9 \times 10^{-4}$ & $-1.6 \times 10^{-2}$ & $-3.7 \times 10^{-2}$ & $6.4 \times 10^{-2}$ & $-1.5 \times 10^{-2}$ & $-4.8 \times 10^{-3}$ & 0.10 & 0.11 \\
\hline MYS & SEASI & Low & 45 & $-4.9 \times 10^{-2}$ & 0.11 & $3.5 \times 10^{-2}$ & $-6.7 \times 10^{-2}$ & $4.8 \times 10^{-3}$ & $3.0 \times 10^{-2}$ & 0.12 & $9.2 \times 10^{-2}$ \\
\hline PHL & SEASI & Low & 51 & $5.4 \times 10^{-2}$ & $-1.1 \times 10^{-2}$ & $-3.3 \times 10^{-4}$ & $6.1 \times 10^{-3}$ & $-4.2 \times 10^{-2}$ & $6.5 \times 10^{-3}$ & 0.10 & $9.5 \times 10^{-2}$ \\
\hline $\mathrm{AZE}$ & WASI & Low & 48 & 0.12 & $-2.9 \times 10^{-3}$ & $-9.7 \times 10^{-3}$ & -0.17 & $9.3 \times 10^{-2}$ & $3.4 \times 10^{-2}$ & 0.14 & 0.11 \\
\hline HUN & EEUR & Low & 50 & $-5.6 \times 10^{-3}$ & 3.9 & $-1.7 \times 10^{-2}$ & -2.8 & -1.1 & $1.7 \times 10^{-2}$ & 0.12 & 0.11 \\
\hline UKR & EEUR & Low & 48 & 0.50 & 0.44 & $-1.1 \times 10^{-2}$ & -0.93 & $5.7 \times 10^{-2}$ & $6.3 \times 10^{-2}$ & 0.17 & 0.11 \\
\hline FIN & NEUR & Low & 33 & $-1.1 \times 10^{-2}$ & 3.7 & $-2.3 \times 10^{-2}$ & 0.73 & -4.3 & $9.8 \times 10^{-2}$ & 0.13 & $3.4 \times 10^{-2}$ \\
\hline IRL & NEUR & Low & 32 & $-4.0 \times 10^{-3}$ & 0.30 & $2.3 \times 10^{-2}$ & -0.11 & -0.12 & $9.1 \times 10^{-2}$ & 0.12 & $3.0 \times 10^{-2}$ \\
\hline GBR & NEUR & Low & 37 & -0.14 & -0.16 & $5.3 \times 10^{-3}$ & $3.9 \times 10^{-2}$ & 0.39 & 0.13 & 0.16 & $3.5 \times 10^{-2}$ \\
\hline ALB & SEUR & Low & 44 & $-5.6 \times 10^{-3}$ & $4.3 \times 10^{-2}$ & $-1.2 \times 10^{-2}$ & $2.2 \times 10^{-2}$ & $1.6 \times 10^{-2}$ & $6.3 \times 10^{-2}$ & 0.11 & $4.2 \times 10^{-2}$ \\
\hline GRC & SEUR & Low & 60 & $3.1 \times 10^{-2}$ & $-1.2 \times 10^{-2}$ & $9.2 \times 10^{-3}$ & $-2.2 \times 10^{-2}$ & $8.6 \times 10^{-3}$ & $1.4 \times 10^{-2}$ & 0.12 & 0.11 \\
\hline HRV & SEUR & Low & 47 & $-1.5 \times 10^{-2}$ & 5.1 & $-6.9 \times 10^{-2}$ & $-6.2 \times 10^{-3}$ & -4.9 & 0.13 & 0.17 & $4.3 \times 10^{-2}$ \\
\hline PRT & SEUR & Low & 54 & $1.1 \times 10^{-2}$ & $-6.5 \times 10^{-3}$ & $-2.0 \times 10^{-2}$ & $-2.6 \times 10^{-2}$ & $3.9 \times 10^{-2}$ & $-2.2 \times 10^{-3}$ & 0.11 & 0.11 \\
\hline
\end{tabular}


Table A1. Cont.

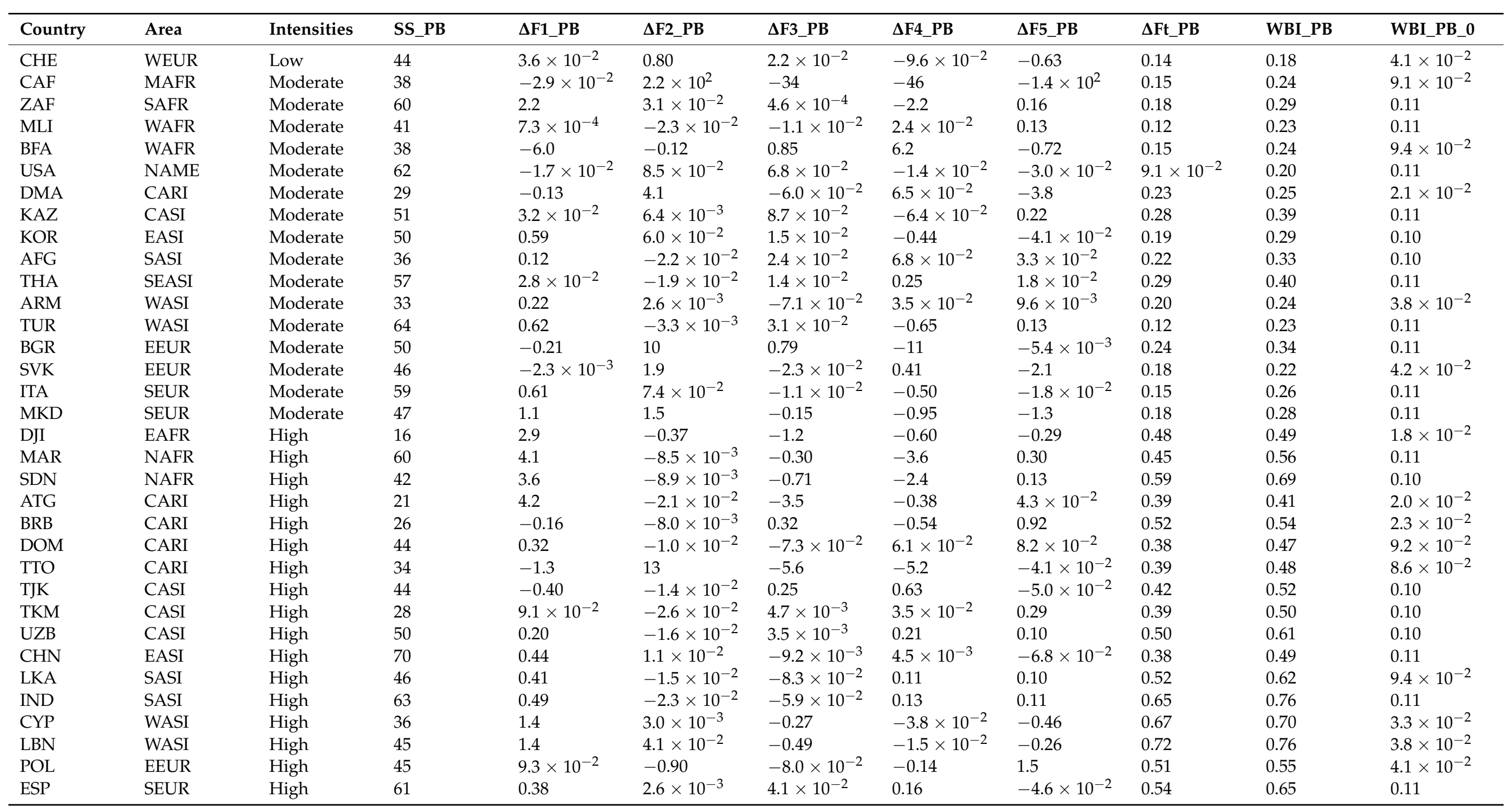


Table A1. Cont.

\begin{tabular}{|c|c|c|c|c|c|c|c|c|c|c|c|}
\hline Country & Area & Intensities & SS_PB & $\Delta$ F1_PB & $\Delta \mathrm{F} 2 \_P B$ & $\Delta$ F3_PB & $\Delta \mathrm{F} 4 \_\mathrm{PB}$ & $\Delta$ F5_PB & $\Delta \mathrm{Ft} \_\mathrm{PB}$ & WBI_PB & WBI_PB_0 \\
\hline AUT & WEUR & High & 42 & $-2.4 \times 10^{-3}$ & 1.9 & -0.12 & 2.5 & -3.8 & 0.47 & 0.52 & $4.1 \times 10^{-2}$ \\
\hline FRA & WEUR & High & 53 & -0.51 & 1.1 & 0.11 & $-6.7 \times 10^{-2}$ & -0.21 & 0.47 & 0.58 & 0.11 \\
\hline DZA & NAFR & Very High & 47 & -61 & -7.2 & 16 & 52 & 1.3 & 1.1 & 1.2 & 0.11 \\
\hline TUN & NAFR & Very High & 48 & 1.1 & $-2.8 \times 10^{-3}$ & $8.6 \times 10^{-3}$ & -0.31 & 0.43 & 1.2 & 1.3 & $3.6 \times 10^{-2}$ \\
\hline KNA & CARI & Very High & 22 & -2.3 & -5.9 & 6.6 & 0.30 & 2.9 & 1.5 & 1.5 & $1.4 \times 10^{-2}$ \\
\hline IRN & SASI & Very High & 53 & 0.62 & $-2.6 \times 10^{-2}$ & $-3.8 \times 10^{-2}$ & 0.20 & 0.46 & 1.2 & 1.3 & 0.11 \\
\hline PAK & SASI & Very High & 55 & 0.92 & $-2.7 \times 10^{-2}$ & -0.10 & $9.5 \times 10^{-2}$ & 0.66 & 1.5 & 1.7 & 0.11 \\
\hline JOR & WASI & Very High & 33 & 20 & $-8.9 \times 10^{-2}$ & -6.9 & -3.1 & -7.5 & 2.6 & 2.6 & $3.5 \times 10^{-2}$ \\
\hline KWT & WASI & Very High & 24 & $1.1 \times 10^{4}$ & -4.6 & $-4.6 \times 10^{3}$ & $-6.2 \times 10^{3}$ & $-1.5 \times 10^{2}$ & 26 & 26 & $3.2 \times 10^{-2}$ \\
\hline SAU & WASI & Very High & 31 & -5.3 & $-5.2 \times 10^{-3}$ & 4.2 & 6.3 & 0.33 & 5.4 & 5.5 & $3.2 \times 10^{-2}$ \\
\hline $\mathrm{OMN}$ & WASI & Very High & 22 & 1.9 & $-2.9 \times 10^{-3}$ & -0.54 & -0.61 & 0.12 & 0.85 & 0.88 & $2.7 \times 10^{-2}$ \\
\hline ARE & WASI & Very High & 26 & $7.7 \times 10^{2}$ & $-2.0 \times 10^{-3}$ & $-2.0 \times 10^{2}$ & $-5.5 \times 10^{2}$ & -4.8 & 23 & 23 & $3.3 \times 10^{-2}$ \\
\hline YEM & WASI & Very High & 37 & -6.7 & $-4.8 \times 10^{-3}$ & 6.0 & 2.4 & 1.3 & 2.9 & 2.9 & $3.5 \times 10^{-2}$ \\
\hline MDA & EEUR & Very High & 43 & 0.49 & 1.4 & $4.7 \times 10^{-2}$ & -0.50 & 1.4 & 2.8 & 2.8 & $4.1 \times 10^{-2}$ \\
\hline CZE & EEUR & Very High & 45 & -4.9 & 20 & -0.99 & 15 & -25 & 4.6 & 4.7 & $4.1 \times 10^{-2}$ \\
\hline MLT & SEUR & Very High & 29 & -12 & $-7.4 \times 10^{-2}$ & 6.6 & -2.3 & 9.7 & 1.6 & 1.6 & $3.1 \times 10^{-2}$ \\
\hline SVN & SEUR & Very High & 44 & $-8.5 \times 10^{-3}$ & $1.2 \times 10^{3}$ & -45 & -13 & $-1.1 \times 10^{3}$ & 1.2 & 1.3 & $3.8 \times 10^{-2}$ \\
\hline DEU & WEUR & Very High & 44 & -0.20 & 2.2 & $-8.8 \times 10^{-2}$ & 1.4 & -1.6 & 1.7 & 1.8 & $4.1 \times 10^{-2}$ \\
\hline NLD & WEUR & Very High & 41 & -0.19 & -3.9 & $-5.2 \times 10^{-2}$ & -2.8 & 16 & 8.9 & 8.9 & $3.9 \times 10^{-2}$ \\
\hline BEL & WEUR & Very High & 44 & 1.7 & -19 & $-2.7 \times 10^{-2}$ & -6.1 & 42 & 19 & 19 & $4.0 \times 10^{-2}$ \\
\hline LUX & WEUR & Very High & 36 & -0.46 & $-2.1 \times 10^{2}$ & 0.59 & 48 & $1.7 \times 10^{2}$ & 2.0 & 2.1 & $3.6 \times 10^{-2}$ \\
\hline
\end{tabular}

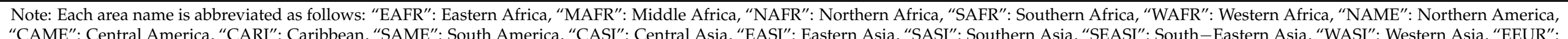

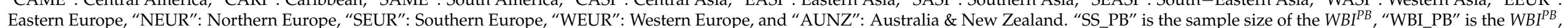

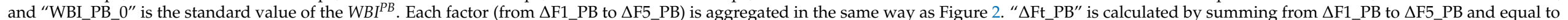
the difference between WBI_PB and WBI_PB_0. 
Table A2. Decomposition results of $W B I^{C B}$ (unit: \%).

\begin{tabular}{|c|c|c|c|c|c|c|c|c|c|c|c|c|}
\hline Country & Area & Intensities & SS_CB & $\Delta \mathrm{F} 1 \_\mathrm{CB}$ & $\Delta \mathrm{F} 2 \_\mathrm{CB}$ & $\Delta \mathrm{F} 3 \_\mathrm{CB}$ & $\Delta \mathrm{F} 4 \_\mathrm{CB}$ & $\Delta \mathrm{F} 5 \_\mathrm{CB}$ & $\Delta \mathrm{F} 6 \_\mathrm{CB}$ & $\Delta F t \_C B$ & WBI_CB & WBI_CB_0 \\
\hline MWI & EAFR & Very Low & 725 & 2.0 & $-1.9 \times 10^{-3}$ & $3.0 \times 10^{-2}$ & $3.7 \times 10^{2}$ & $-5.7 \times 10^{2}$ & $2.0 \times 10^{2}$ & $-3.7 \times 10^{-2}$ & $4.7 \times 10^{-2}$ & $8.4 \times 10^{-2}$ \\
\hline $\mathrm{MOZ}$ & EAFR & Very Low & 560 & $-1.5 \times 10^{-3}$ & $-4.2 \times 10^{-4}$ & $-1.8 \times 10^{-3}$ & $-1.8 \times 10^{-2}$ & -0.13 & 0.12 & $-2.8 \times 10^{-2}$ & $5.8 \times 10^{-2}$ & $8.6 \times 10^{-2}$ \\
\hline $\mathrm{TZA}$ & EAFR & Very Low & 1376 & -0.16 & $-7.8 \times 10^{-3}$ & $2.6 \times 10^{-2}$ & $1.2 \times 10^{2}$ & $-1.2 \times 10^{2}$ & 0.28 & $8.9 \times 10^{-3}$ & $9.4 \times 10^{-2}$ & $8.5 \times 10^{-2}$ \\
\hline ETH & EAFR & Very Low & 1303 & 0.82 & $-3.9 \times 10^{-3}$ & $2.5 \times 10^{-3}$ & -0.68 & -0.37 & 0.21 & $-2.7 \times 10^{-2}$ & $6.1 \times 10^{-2}$ & $8.7 \times 10^{-2}$ \\
\hline $\mathrm{ZMB}$ & EAFR & Very Low & 759 & $5.3 \times 10^{-3}$ & $-7.9 \times 10^{-4}$ & $-3.9 \times 10^{-4}$ & 0.32 & -0.41 & $1.1 \times 10^{-2}$ & $-6.7 \times 10^{-2}$ & $2.0 \times 10^{-2}$ & $8.7 \times 10^{-2}$ \\
\hline AGO & MAFR & Very Low & 746 & $4.8 \times 10^{-2}$ & 0.55 & 0.40 & $8.2 \times 10^{3}$ & $-8.2 \times 10^{3}$ & 2.1 & $-7.4 \times 10^{-3}$ & $7.9 \times 10^{-2}$ & $8.7 \times 10^{-2}$ \\
\hline CMR & MAFR & Very Low & 1066 & $-1.1 \times 10^{-2}$ & $4.8 \times 10^{-4}$ & $5.0 \times 10^{-4}$ & 2.3 & -2.4 & $3.8 \times 10^{-2}$ & $-6.9 \times 10^{-2}$ & $1.7 \times 10^{-2}$ & $8.6 \times 10^{-2}$ \\
\hline COG & MAFR & Very Low & 845 & $-7.2 \times 10^{-3}$ & $6.6 \times 10^{-2}$ & $1.6 \times 10^{-2}$ & $2.8 \times 10^{-2}$ & -0.20 & $8.3 \times 10^{-3}$ & $-8.5 \times 10^{-2}$ & $1.1 \times 10^{-3}$ & $8.6 \times 10^{-2}$ \\
\hline GAB & MAFR & Very Low & 569 & $-3.1 \times 10^{-2}$ & $1.7 \times 10^{-2}$ & $-6.7 \times 10^{-6}$ & $-3.5 \times 10^{-3}$ & $-5.1 \times 10^{-2}$ & $-7.9 \times 10^{-3}$ & $-7.7 \times 10^{-2}$ & $9.6 \times 10^{-3}$ & $8.6 \times 10^{-2}$ \\
\hline NAM & SAFR & Very Low & 433 & $-1.8 \times 10^{-2}$ & $4.8 \times 10^{-5}$ & $-6.0 \times 10^{-3}$ & 0.23 & -0.30 & $2.4 \times 10^{-2}$ & $-7.6 \times 10^{-2}$ & $1.1 \times 10^{-2}$ & $8.7 \times 10^{-2}$ \\
\hline GIN & WAFR & Very Low & 602 & $-3.8 \times 10^{-2}$ & $1.7 \times 10^{-2}$ & $8.2 \times 10^{-5}$ & 8.0 & -8.4 & 0.41 & $-1.4 \times 10^{-2}$ & $7.1 \times 10^{-2}$ & $8.5 \times 10^{-2}$ \\
\hline GNB & WAFR & Very Low & 255 & $-3.3 \times 10^{-2}$ & $-3.3 \times 10^{-3}$ & $-1.2 \times 10^{-3}$ & $-3.7 \times 10^{-3}$ & $1.8 \times 10^{-5}$ & $2.0 \times 10^{-2}$ & $-2.1 \times 10^{-2}$ & $6.5 \times 10^{-2}$ & $8.6 \times 10^{-2}$ \\
\hline CAN & NAME & Very Low & 4227 & $-9.3 \times 10^{-3}$ & $-4.1 \times 10^{-2}$ & $-1.6 \times 10^{-2}$ & 1.1 & -17 & 16 & $-4.0 \times 10^{-2}$ & $4.7 \times 10^{-2}$ & $8.7 \times 10^{-2}$ \\
\hline USA & NAME & Very Low & 6891 & $-4.9 \times 10^{-3}$ & -0.35 & $-7.0 \times 10^{-2}$ & 0.66 & -0.87 & 0.64 & $8.9 \times 10^{-3}$ & $9.6 \times 10^{-2}$ & $8.7 \times 10^{-2}$ \\
\hline BLZ & CAME & Very Low & 522 & $-3.3 \times 10^{-2}$ & $2.9 \times 10^{-4}$ & $5.8 \times 10^{-4}$ & $1.3 \times 10^{-2}$ & -2.8 & 2.7 & $-8.2 \times 10^{-2}$ & $3.6 \times 10^{-3}$ & $8.6 \times 10^{-2}$ \\
\hline GTM & CAME & Very Low & 1405 & $-4.9 \times 10^{-4}$ & $2.1 \times 10^{-2}$ & $7.7 \times 10^{-3}$ & 29 & -29 & 0.24 & $-6.2 \times 10^{-2}$ & $2.5 \times 10^{-2}$ & $8.6 \times 10^{-2}$ \\
\hline HND & CAME & Very Low & 897 & $-7.2 \times 10^{-3}$ & $-1.5 \times 10^{-4}$ & $1.1 \times 10^{-3}$ & 2.2 & -2.3 & 0.13 & $-5.6 \times 10^{-2}$ & $3.1 \times 10^{-2}$ & $8.6 \times 10^{-2}$ \\
\hline NIC & CAME & Very Low & 808 & $-3.1 \times 10^{-2}$ & $8.4 \times 10^{-4}$ & $2.2 \times 10^{-3}$ & 26 & -33 & 6.9 & $-7.1 \times 10^{-2}$ & $1.6 \times 10^{-2}$ & $8.7 \times 10^{-2}$ \\
\hline PAN & CAME & Very Low & 1265 & $-3.7 \times 10^{-2}$ & $1.6 \times 10^{-2}$ & $6.3 \times 10^{-3}$ & 1.6 & -1.7 & $2.5 \times 10^{-2}$ & $-6.8 \times 10^{-2}$ & $1.9 \times 10^{-2}$ & $8.7 \times 10^{-2}$ \\
\hline ARG & SAME & Very Low & 3414 & $-4.4 \times 10^{-3}$ & $7.5 \times 10^{-4}$ & $-3.8 \times 10^{-3}$ & $8.5 \times 10^{4}$ & $-8.5 \times 10^{4}$ & 72 & $-7.3 \times 10^{-2}$ & $1.5 \times 10^{-2}$ & $8.7 \times 10^{-2}$ \\
\hline $\mathrm{BOL}$ & SAME & Very Low & 845 & $-4.4 \times 10^{-2}$ & $1.4 \times 10^{-3}$ & $5.4 \times 10^{-2}$ & 37 & $-7.5 \times 10^{2}$ & $7.2 \times 10^{2}$ & $-8.3 \times 10^{-2}$ & $3.5 \times 10^{-3}$ & $8.6 \times 10^{-2}$ \\
\hline BRA & SAME & Very Low & 3429 & $-3.6 \times 10^{-2}$ & $3.1 \times 10^{-3}$ & $-5.5 \times 10^{-4}$ & 3.6 & -4.2 & 0.51 & $-7.5 \times 10^{-2}$ & $1.2 \times 10^{-2}$ & $8.7 \times 10^{-2}$ \\
\hline $\mathrm{CHL}$ & SAME & Very Low & 2300 & $2.3 \times 10^{-2}$ & $3.2 \times 10^{-3}$ & $-7.5 \times 10^{-4}$ & 0.99 & -1.5 & 0.44 & $-8.0 \times 10^{-2}$ & $7.1 \times 10^{-3}$ & $8.7 \times 10^{-2}$ \\
\hline $\mathrm{COL}$ & SAME & Very Low & 1617 & $-5.2 \times 10^{-2}$ & $4.6 \times 10^{-3}$ & $-5.4 \times 10^{-4}$ & $8.2 \times 10^{-2}$ & -0.40 & 0.29 & $-7.8 \times 10^{-2}$ & $8.1 \times 10^{-3}$ & $8.7 \times 10^{-2}$ \\
\hline ECU & SAME & Very Low & 1203 & $-3.4 \times 10^{-2}$ & $-2.0 \times 10^{-3}$ & $-2.1 \times 10^{-4}$ & 11 & -11 & 0.19 & $-6.7 \times 10^{-2}$ & $1.9 \times 10^{-2}$ & $8.7 \times 10^{-2}$ \\
\hline GUY & SAME & Very Low & 720 & 4.8 & $7.3 \times 10^{-2}$ & -0.60 & -1.4 & -2.6 & -0.32 & $-8.4 \times 10^{-2}$ & $2.4 \times 10^{-3}$ & $8.6 \times 10^{-2}$ \\
\hline PRY & SAME & Very Low & 908 & $7.5 \times 10^{-2}$ & $1.8 \times 10^{-3}$ & $-3.3 \times 10^{-2}$ & 4.6 & $-7.9 \times 10^{2}$ & $7.8 \times 10^{2}$ & $-8.3 \times 10^{-2}$ & $2.8 \times 10^{-3}$ & $8.6 \times 10^{-2}$ \\
\hline PER & SAME & Very Low & 1714 & $-4.4 \times 10^{-2}$ & $-2.3 \times 10^{-3}$ & $6.1 \times 10^{-4}$ & 0.16 & -0.25 & $5.9 \times 10^{-2}$ & $-7.6 \times 10^{-2}$ & $1.1 \times 10^{-2}$ & $8.7 \times 10^{-2}$ \\
\hline SUR & SAME & Very Low & 727 & 1.0 & $3.2 \times 10^{-4}$ & $-2.5 \times 10^{-2}$ & -0.35 & -0.67 & $-4.8 \times 10^{-2}$ & $-8.0 \times 10^{-2}$ & $5.4 \times 10^{-3}$ & $8.6 \times 10^{-2}$ \\
\hline URY & SAME & Very Low & 1432 & 1.1 & $3.2 \times 10^{-2}$ & -0.20 & 4.8 & -7.4 & 1.7 & $-8.1 \times 10^{-2}$ & $6.0 \times 10^{-3}$ & $8.7 \times 10^{-2}$ \\
\hline
\end{tabular}


Table A2. Cont.

\begin{tabular}{|c|c|c|c|c|c|c|c|c|c|c|c|c|}
\hline Country & Area & Intensities & SS_CB & $\Delta \mathrm{F} 1 \_\mathrm{CB}$ & $\Delta \mathrm{F} 2 \_\mathrm{CB}$ & $\Delta \mathrm{F} 3 \_\mathrm{CB}$ & $\Delta \mathrm{F} 4 \_\mathrm{CB}$ & $\Delta \mathrm{F} 5 \_\mathrm{CB}$ & $\Delta \mathrm{F} 6 \_\mathrm{CB}$ & $\Delta F t \_C B$ & WBI_CB & WBI_CB_0 \\
\hline VEN & SAME & Very Low & 1014 & $-5.0 \times 10^{-2}$ & $7.2 \times 10^{-4}$ & $9.2 \times 10^{-4}$ & 58 & -58 & $4.0 \times 10^{-2}$ & $-7.8 \times 10^{-2}$ & $9.6 \times 10^{-3}$ & $8.7 \times 10^{-2}$ \\
\hline MNG & EASI & Very Low & 523 & $-8.1 \times 10^{-3}$ & $4.4 \times 10^{-2}$ & $4.8 \times 10^{-3}$ & 0.28 & -0.43 & $6.5 \times 10^{-2}$ & $-4.3 \times 10^{-2}$ & $4.4 \times 10^{-2}$ & $8.7 \times 10^{-2}$ \\
\hline BGD & SASI & Very Low & 763 & $-1.6 \times 10^{-4}$ & $-1.3 \times 10^{-2}$ & $-8.4 \times 10^{-3}$ & $8.5 \times 10^{-2}$ & $-4.2 \times 10^{-2}$ & $-1.2 \times 10^{-2}$ & $9.0 \times 10^{-3}$ & $9.3 \times 10^{-2}$ & $8.4 \times 10^{-2}$ \\
\hline MMR & SEASI & Very Low & 384 & $-4.0 \times 10^{-2}$ & $-4.8 \times 10^{-3}$ & $-4.6 \times 10^{-5}$ & 0.11 & -0.14 & $4.0 \times 10^{-3}$ & $-7.1 \times 10^{-2}$ & $1.3 \times 10^{-2}$ & $8.4 \times 10^{-2}$ \\
\hline IDN & SEASI & Very Low & 2443 & $-1.8 \times 10^{-3}$ & $-9.4 \times 10^{-3}$ & $1.3 \times 10^{-3}$ & 1.1 & $-7.1 \times 10^{2}$ & $7.1 \times 10^{2}$ & $-1.5 \times 10^{-2}$ & $7.0 \times 10^{-2}$ & $8.5 \times 10^{-2}$ \\
\hline KHM & SEASI & Very Low & 621 & $-4.3 \times 10^{-2}$ & $-4.2 \times 10^{-3}$ & $5.4 \times 10^{-4}$ & 17 & -17 & 0.16 & $-6.2 \times 10^{-2}$ & $2.2 \times 10^{-2}$ & $8.4 \times 10^{-2}$ \\
\hline $\mathrm{LAO}$ & SEASI & Very Low & 158 & $-5.9 \times 10^{-2}$ & $-3.1 \times 10^{-3}$ & $2.2 \times 10^{-3}$ & 1.9 & -2.0 & 0.16 & $-7.3 \times 10^{-2}$ & $1.1 \times 10^{-2}$ & $8.4 \times 10^{-2}$ \\
\hline VNM & SEASI & Very Low & 1787 & $-4.2 \times 10^{-3}$ & $-6.7 \times 10^{-3}$ & $4.8 \times 10^{-3}$ & 11 & $-1.9 \times 10^{3}$ & $1.9 \times 10^{3}$ & $-3.2 \times 10^{-2}$ & $5.4 \times 10^{-2}$ & $8.6 \times 10^{-2}$ \\
\hline GEO & WASI & Very Low & 1296 & $-1.2 \times 10^{-2}$ & $1.0 \times 10^{-2}$ & $1.6 \times 10^{-4}$ & 0.13 & -0.21 & $1.5 \times 10^{-2}$ & $-6.9 \times 10^{-2}$ & $1.8 \times 10^{-2}$ & $8.7 \times 10^{-2}$ \\
\hline BLR & EEUR & Very Low & 1523 & $4.5 \times 10^{-2}$ & 0.26 & $1.0 \times 10^{-2}$ & $-7.2 \times 10^{-2}$ & -0.24 & $-2.9 \times 10^{-2}$ & $-2.5 \times 10^{-2}$ & $6.1 \times 10^{-2}$ & $8.6 \times 10^{-2}$ \\
\hline ROU & EEUR & Very Low & 2110 & $-4.4 \times 10^{-3}$ & 0.45 & $-6.3 \times 10^{-4}$ & 47 & -48 & 0.22 & $-7.5 \times 10^{-3}$ & $7.9 \times 10^{-2}$ & $8.7 \times 10^{-2}$ \\
\hline RUS & EEUR & Very Low & 3154 & $-3.5 \times 10^{-2}$ & 0.28 & $5.4 \times 10^{-3}$ & 3.9 & -4.5 & 0.27 & $-5.0 \times 10^{-2}$ & $3.6 \times 10^{-2}$ & $8.6 \times 10^{-2}$ \\
\hline ISL & NEUR & Very Low & 998 & $7.4 \times 10^{-2}$ & $1.2 \times 10^{-3}$ & $1.3 \times 10^{-3}$ & $-9.9 \times 10^{-2}$ & -0.12 & $5.4 \times 10^{-2}$ & $-8.5 \times 10^{-2}$ & $7.5 \times 10^{-4}$ & $8.6 \times 10^{-2}$ \\
\hline IRL & NEUR & Very Low & 2284 & $4.0 \times 10^{-3}$ & 0.57 & $-6.1 \times 10^{-3}$ & $-2.9 \times 10^{-2}$ & -2.1 & 1.5 & $9.8 \times 10^{-3}$ & $9.7 \times 10^{-2}$ & $8.7 \times 10^{-2}$ \\
\hline LVA & NEUR & Very Low & 1701 & $-9.1 \times 10^{-3}$ & 0.43 & $3.2 \times 10^{-4}$ & 0.14 & -27 & 26 & $-3.8 \times 10^{-2}$ & $4.1 \times 10^{-2}$ & $7.9 \times 10^{-2}$ \\
\hline GRC & SEUR & Very Low & 2683 & $3.1 \times 10^{-2}$ & $-2.5 \times 10^{-3}$ & $4.4 \times 10^{-3}$ & 15 & -15 & $9.6 \times 10^{-2}$ & $-1.6 \times 10^{-2}$ & $7.1 \times 10^{-2}$ & $8.7 \times 10^{-2}$ \\
\hline PRT & SEUR & Very Low & 2552 & $9.0 \times 10^{-3}$ & $-1.2 \times 10^{-3}$ & $4.8 \times 10^{-3}$ & 0.16 & -0.26 & $8.6 \times 10^{-2}$ & $-2.4 \times 10^{-3}$ & $8.5 \times 10^{-2}$ & $8.7 \times 10^{-2}$ \\
\hline AUS & AUNZ & Very Low & 3519 & $1.0 \times 10^{-2}$ & $5.9 \times 10^{-3}$ & $-5.0 \times 10^{-3}$ & 0.44 & $-3.9 \times 10^{2}$ & $3.9 \times 10^{2}$ & $-5.8 \times 10^{-2}$ & $2.9 \times 10^{-2}$ & $8.7 \times 10^{-2}$ \\
\hline NZL & AUNZ & Very Low & 2526 & 0.27 & $1.3 \times 10^{-3}$ & $-2.9 \times 10^{-2}$ & -0.10 & -0.71 & 0.49 & $-8.1 \times 10^{-2}$ & $5.6 \times 10^{-3}$ & $8.7 \times 10^{-2}$ \\
\hline FJI & MELA & Very Low & 770 & $-2.7 \times 10^{-2}$ & $4.3 \times 10^{-3}$ & $4.9 \times 10^{-4}$ & 0.18 & -0.46 & 0.23 & $-7.5 \times 10^{-2}$ & $1.2 \times 10^{-2}$ & $8.7 \times 10^{-2}$ \\
\hline MDG & EAFR & Low & 921 & $-3.0 \times 10^{-2}$ & $-1.1 \times 10^{-2}$ & $-4.5 \times 10^{-3}$ & $5.4 \times 10^{-2}$ & -0.12 & 0.14 & $2.8 \times 10^{-2}$ & 0.11 & $8.2 \times 10^{-2}$ \\
\hline ZWE & EAFR & Low & 837 & 1.0 & $-1.4 \times 10^{-3}$ & $4.0 \times 10^{-2}$ & 0.50 & -1.9 & 0.37 & $5.1 \times 10^{-2}$ & 0.14 & $8.7 \times 10^{-2}$ \\
\hline RWA & EAFR & Low & 558 & 4.7 & $4.3 \times 10^{-3}$ & $3.3 \times 10^{-2}$ & $2.3 \times 10^{2}$ & $-4.2 \times 10^{2}$ & $1.9 \times 10^{2}$ & $5.1 \times 10^{-2}$ & 0.13 & $8.4 \times 10^{-2}$ \\
\hline BWA & SAFR & Low & 418 & $4.9 \times 10^{-2}$ & 0.12 & 0.11 & $1.1 \times 10^{2}$ & $-1.1 \times 10^{2}$ & $6.8 \times 10^{-2}$ & $8.9 \times 10^{-2}$ & 0.18 & $8.7 \times 10^{-2}$ \\
\hline SWZ & SAFR & Low & 346 & 0.12 & $1.0 \times 10^{-2}$ & $2.0 \times 10^{-2}$ & 2.2 & -2.3 & $-7.9 \times 10^{-3}$ & $1.8 \times 10^{-2}$ & 0.10 & $8.7 \times 10^{-2}$ \\
\hline GHA & WAFR & Low & 1754 & -2.6 & $2.3 \times 10^{-3}$ & -0.27 & 4.7 & -16 & 14 & $5.8 \times 10^{-2}$ & 0.14 & $8.5 \times 10^{-2}$ \\
\hline LBR & WAFR & Low & 533 & $-5.0 \times 10^{-2}$ & 0.11 & $4.5 \times 10^{-2}$ & 2.8 & -2.9 & $-1.4 \times 10^{-2}$ & $4.2 \times 10^{-2}$ & 0.13 & $8.4 \times 10^{-2}$ \\
\hline MLI & WAFR & Low & 519 & $6.0 \times 10^{-4}$ & $-2.0 \times 10^{-2}$ & $-1.7 \times 10^{-3}$ & $8.6 \times 10^{-3}$ & $-2.4 \times 10^{-2}$ & $9.6 \times 10^{-2}$ & $6.0 \times 10^{-2}$ & 0.15 & $8.7 \times 10^{-2}$ \\
\hline MRT & WAFR & Low & 662 & 0.41 & $-6.9 \times 10^{-3}$ & $-4.2 \times 10^{-3}$ & $-5.1 \times 10^{-2}$ & -0.35 & 0.11 & 0.10 & 0.19 & $8.7 \times 10^{-2}$ \\
\hline NGA & WAFR & Low & 1022 & 1.1 & $-3.7 \times 10^{-2}$ & $3.4 \times 10^{-3}$ & 4.7 & -6.3 & 0.62 & $9.7 \times 10^{-2}$ & 0.18 & $8.6 \times 10^{-2}$ \\
\hline
\end{tabular}


Table A2. Cont.

\begin{tabular}{|c|c|c|c|c|c|c|c|c|c|c|c|c|}
\hline Country & Area & Intensities & SS_CB & $\Delta \mathrm{F} 1 \_\mathrm{CB}$ & $\Delta \mathrm{F} 2 \_\mathrm{CB}$ & $\Delta \mathrm{F} 3 \_\mathrm{CB}$ & $\Delta \mathrm{F} 4 \_\mathrm{CB}$ & $\Delta \mathrm{F} 5 \_\mathrm{CB}$ & $\Delta \mathrm{F} 6 \_\mathrm{CB}$ & $\Delta \mathrm{Ft} \_\mathrm{CB}$ & WBI_CB & WBI_CB_0 \\
\hline SEN & WAFR & Low & 1383 & $-3.2 \times 10^{-2}$ & $-8.7 \times 10^{-3}$ & $1.4 \times 10^{-2}$ & 0.56 & -2.0 & 1.5 & $9.3 \times 10^{-2}$ & 0.18 & $8.7 \times 10^{-2}$ \\
\hline SLE & WAFR & Low & 418 & $-4.0 \times 10^{-2}$ & $8.4 \times 10^{-2}$ & $4.2 \times 10^{-4}$ & $-2.7 \times 10^{-2}$ & -0.13 & 0.15 & $3.5 \times 10^{-2}$ & 0.12 & $8.5 \times 10^{-2}$ \\
\hline TGO & WAFR & Low & 949 & 5.7 & 2.0 & 1.0 & 9.1 & -17 & -0.56 & $8.2 \times 10^{-2}$ & 0.17 & $8.6 \times 10^{-2}$ \\
\hline JAM & CARI & Low & 936 & 0.20 & $4.0 \times 10^{-2}$ & $3.8 \times 10^{-3}$ & $1.5 \times 10^{-2}$ & -0.25 & $6.6 \times 10^{-2}$ & $7.2 \times 10^{-2}$ & 0.16 & $8.6 \times 10^{-2}$ \\
\hline KGZ & CASI & Low & 795 & $8.6 \times 10^{-2}$ & $-6.2 \times 10^{-3}$ & $6.8 \times 10^{-4}$ & $5.3 \times 10^{-2}$ & -0.14 & $3.5 \times 10^{-2}$ & $2.6 \times 10^{-2}$ & 0.11 & $8.7 \times 10^{-2}$ \\
\hline JPN & EASI & Low & 2503 & $-1.9 \times 10^{-2}$ & $3.2 \times 10^{-3}$ & $3.2 \times 10^{-2}$ & 1.1 & -1.2 & $9.1 \times 10^{-2}$ & $4.5 \times 10^{-2}$ & 0.13 & $8.7 \times 10^{-2}$ \\
\hline MYS & SEASI & Low & 3244 & $-3.1 \times 10^{-2}$ & 0.11 & $4.1 \times 10^{-5}$ & 10 & -11 & 0.15 & $5.8 \times 10^{-2}$ & 0.14 & $8.6 \times 10^{-2}$ \\
\hline THA & SEASI & Low & 3312 & $2.0 \times 10^{-2}$ & $2.5 \times 10^{-2}$ & $1.5 \times 10^{-2}$ & $2.2 \times 10^{3}$ & $-2.2 \times 10^{3}$ & 0.59 & $9.0 \times 10^{-2}$ & 0.18 & $8.7 \times 10^{-2}$ \\
\hline AZE & WASI & Low & 1166 & 0.15 & $-1.2 \times 10^{-3}$ & $1.4 \times 10^{-3}$ & $-2.9 \times 10^{-2}$ & -0.14 & $4.1 \times 10^{-2}$ & $2.4 \times 10^{-2}$ & 0.11 & $8.7 \times 10^{-2}$ \\
\hline TUR & WASI & Low & 4002 & 0.52 & $-1.9 \times 10^{-3}$ & $4.4 \times 10^{-2}$ & $4.8 \times 10^{2}$ & $-4.8 \times 10^{2}$ & 0.13 & $8.3 \times 10^{-2}$ & 0.17 & $8.7 \times 10^{-2}$ \\
\hline HUN & EEUR & Low & 2426 & $-2.3 \times 10^{-3}$ & 3.8 & $5.8 \times 10^{-4}$ & 3.6 & -13 & 5.8 & $3.8 \times 10^{-2}$ & 0.13 & $8.7 \times 10^{-2}$ \\
\hline UKR & EEUR & Low & 2700 & 0.46 & 0.55 & $4.9 \times 10^{-3}$ & $-7.7 \times 10^{-2}$ & $-1.9 \times 10^{3}$ & $1.9 \times 10^{3}$ & $2.0 \times 10^{-2}$ & 0.11 & $8.5 \times 10^{-2}$ \\
\hline LTU & NEUR & Low & 1901 & $2.6 \times 10^{-3}$ & 1.7 & $-7.6 \times 10^{-3}$ & 5.4 & -25 & 18 & $2.6 \times 10^{-2}$ & 0.11 & $8.6 \times 10^{-2}$ \\
\hline ITA & SEUR & Low & 5602 & 0.50 & $5.9 \times 10^{-2}$ & $2.0 \times 10^{-2}$ & 2.9 & -3.5 & $9.0 \times 10^{-2}$ & $9.2 \times 10^{-2}$ & 0.18 & $8.7 \times 10^{-2}$ \\
\hline CAF & MAFR & Moderate & 354 & $-2.6 \times 10^{-2}$ & $1.9 \times 10^{2}$ & 8.7 & -76 & -6.2 & $-1.1 \times 10^{2}$ & 0.23 & 0.31 & $8.2 \times 10^{-2}$ \\
\hline NER & WAFR & Moderate & 694 & 0.66 & $4.8 \times 10^{-3}$ & $7.2 \times 10^{-4}$ & -0.28 & -0.29 & $4.3 \times 10^{-2}$ & 0.14 & 0.22 & $8.7 \times 10^{-2}$ \\
\hline CUB & CARI & Moderate & 652 & 0.25 & $8.0 \times 10^{-3}$ & $6.7 \times 10^{-3}$ & $1.8 \times 10^{4}$ & $-1.8 \times 10^{4}$ & 15 & 0.14 & 0.23 & $8.4 \times 10^{-2}$ \\
\hline LCA & CARI & Moderate & 349 & 0.55 & $3.9 \times 10^{-6}$ & $-1.4 \times 10^{-2}$ & $-3.6 \times 10^{-2}$ & -0.43 & $7.1 \times 10^{-2}$ & 0.14 & 0.22 & $8.5 \times 10^{-2}$ \\
\hline KAZ & CASI & Moderate & 1454 & $2.5 \times 10^{-2}$ & $5.0 \times 10^{-3}$ & $1.0 \times 10^{-2}$ & 0.41 & -0.68 & 0.39 & 0.15 & 0.24 & $8.7 \times 10^{-2}$ \\
\hline TJK & CASI & Moderate & 336 & $4.2 \times 10^{-3}$ & $-7.0 \times 10^{-3}$ & $2.1 \times 10^{-2}$ & 0.18 & $-2.1 \times 10^{-2}$ & $8.0 \times 10^{-2}$ & 0.26 & 0.34 & $8.5 \times 10^{-2}$ \\
\hline TKM & CASI & Moderate & 329 & $6.8 \times 10^{-2}$ & $-2.0 \times 10^{-2}$ & $1.7 \times 10^{-3}$ & $-1.4 \times 10^{-2}$ & $-1.0 \times 10^{-2}$ & 0.21 & 0.24 & 0.32 & $8.4 \times 10^{-2}$ \\
\hline $\mathrm{CHN}$ & EASI & Moderate & 5681 & 0.34 & $8.8 \times 10^{-3}$ & $-4.6 \times 10^{-4}$ & $2.9 \times 10^{-2}$ & -3.4 & 3.4 & 0.30 & 0.38 & $8.7 \times 10^{-2}$ \\
\hline PRK & EASI & Moderate & 178 & 0.20 & $-5.7 \times 10^{-3}$ & $-3.1 \times 10^{-2}$ & $-1.3 \times 10^{-2}$ & $-3.0 \times 10^{-2}$ & $1.2 \times 10^{-2}$ & 0.13 & 0.22 & $8.4 \times 10^{-2}$ \\
\hline KOR & EASI & Moderate & 2372 & 0.81 & $4.7 \times 10^{-2}$ & $-2.4 \times 10^{-3}$ & 36 & -37 & 0.27 & 0.29 & 0.37 & $8.7 \times 10^{-2}$ \\
\hline AFG & SASI & Moderate & 611 & 0.18 & $-1.7 \times 10^{-2}$ & $1.1 \times 10^{-4}$ & $4.6 \times 10^{-2}$ & $-2.7 \times 10^{-2}$ & $7.1 \times 10^{-2}$ & 0.25 & 0.34 & $8.4 \times 10^{-2}$ \\
\hline ARM & WASI & Moderate & 1038 & 0.44 & $6.0 \times 10^{-3}$ & $3.4 \times 10^{-3}$ & 47 & -48 & $4.4 \times 10^{-2}$ & 0.13 & 0.21 & $8.7 \times 10^{-2}$ \\
\hline IRQ & WASI & Moderate & 735 & 0.32 & $-1.6 \times 10^{-3}$ & $-3.2 \times 10^{-3}$ & $-7.3 \times 10^{-3}$ & -0.19 & $2.4 \times 10^{-2}$ & 0.15 & 0.23 & $8.7 \times 10^{-2}$ \\
\hline BGR & EEUR & Moderate & 2499 & -0.23 & -1.8 & -0.13 & 41 & -67 & 29 & 0.24 & 0.33 & $8.7 \times 10^{-2}$ \\
\hline SVK & EEUR & Moderate & 1688 & $-1.2 \times 10^{-3}$ & 5.0 & $-2.2 \times 10^{-2}$ & 5.6 & -11 & 0.22 & 0.18 & 0.27 & $8.7 \times 10^{-2}$ \\
\hline FIN & NEUR & Moderate & 1750 & $-1.7 \times 10^{-2}$ & 16 & $-9.4 \times 10^{-3}$ & -4.3 & $-2.1 \times 10^{5}$ & $2.1 \times 10^{5}$ & 0.24 & 0.32 & $8.6 \times 10^{-2}$ \\
\hline
\end{tabular}


Table A2. Cont.

\begin{tabular}{|c|c|c|c|c|c|c|c|c|c|c|c|c|}
\hline Country & Area & Intensities & SS_CB & $\Delta \mathrm{F} 1 \_\mathrm{CB}$ & $\Delta \mathrm{F} 2 \_\mathrm{CB}$ & $\Delta \mathrm{F} 3 \_\mathrm{CB}$ & $\Delta \mathrm{F} 4 \_\mathrm{CB}$ & $\Delta \mathrm{F} 5 \_\mathrm{CB}$ & $\Delta \mathrm{F} 6 \_\mathrm{CB}$ & $\Delta \mathrm{Ft} \_\mathrm{CB}$ & WBI_CB & WBI_CB_0 \\
\hline SWE & NEUR & Moderate & 2834 & $-1.5 \times 10^{-2}$ & 4.1 & $-2.2 \times 10^{-2}$ & 17 & -77 & 57 & 0.18 & 0.27 & $8.7 \times 10^{-2}$ \\
\hline HRV & SEUR & Moderate & 1828 & $-2.0 \times 10^{-2}$ & 33 & $-9.6 \times 10^{-3}$ & 5.8 & -35 & -3.5 & 0.23 & 0.31 & $8.7 \times 10^{-2}$ \\
\hline MKD & SEUR & Moderate & 1311 & 0.53 & 0.71 & $4.1 \times 10^{-3}$ & 1.9 & -2.4 & -0.64 & 0.13 & 0.21 & $8.7 \times 10^{-2}$ \\
\hline $\mathrm{CHE}$ & WEUR & Moderate & 2878 & $5.9 \times 10^{-2}$ & 2.0 & $-4.7 \times 10^{-2}$ & 8.8 & -11 & $7.5 \times 10^{-3}$ & 0.30 & 0.38 & $8.7 \times 10^{-2}$ \\
\hline KEN & EAFR & High & 1555 & 58 & $-2.2 \times 10^{-2}$ & 1.1 & -27 & -36 & 4.3 & 0.55 & 0.64 & $8.7 \times 10^{-2}$ \\
\hline MUS & EAFR & High & 1129 & 0.87 & $3.0 \times 10^{-3}$ & $9.1 \times 10^{-4}$ & 0.13 & -0.72 & 0.40 & 0.68 & 0.76 & $8.7 \times 10^{-2}$ \\
\hline SDN & NAFR & High & 844 & 3.2 & $-7.3 \times 10^{-3}$ & $9.9 \times 10^{-3}$ & -1.7 & -1.2 & 0.19 & 0.54 & 0.63 & $8.6 \times 10^{-2}$ \\
\hline BEN & WAFR & High & 829 & 0.64 & 0.18 & $4.7 \times 10^{-3}$ & 32 & -33 & 0.66 & 0.39 & 0.47 & $8.4 \times 10^{-2}$ \\
\hline GMB & WAFR & High & 941 & 0.17 & 0.14 & $3.1 \times 10^{-3}$ & $5.5 \times 10^{-3}$ & $3.9 \times 10^{-2}$ & 0.13 & 0.48 & 0.57 & $8.7 \times 10^{-2}$ \\
\hline BFA & WAFR & High & 799 & 4.2 & -0.20 & $1.1 \times 10^{-2}$ & 0.31 & -4.1 & 0.13 & 0.35 & 0.44 & $8.6 \times 10^{-2}$ \\
\hline DOM & CARI & High & 823 & 0.31 & $-6.5 \times 10^{-3}$ & $-4.2 \times 10^{-3}$ & 0.76 & -1.1 & 0.39 & 0.33 & 0.42 & $8.6 \times 10^{-2}$ \\
\hline GRD & CARI & High & 436 & -4.9 & -5.0 & -0.20 & 0.58 & 9.2 & 0.67 & 0.38 & 0.47 & $8.7 \times 10^{-2}$ \\
\hline HTI & CARI & High & 480 & -2.1 & $-3.6 \times 10^{-3}$ & 0.22 & -0.47 & 3.3 & -0.49 & 0.42 & 0.51 & $8.5 \times 10^{-2}$ \\
\hline UZB & CASI & High & 582 & 0.17 & $-1.1 \times 10^{-2}$ & $3.7 \times 10^{-3}$ & 0.65 & -0.59 & 0.12 & 0.34 & 0.43 & $8.7 \times 10^{-2}$ \\
\hline LKA & SASI & High & 1575 & 0.43 & $-1.2 \times 10^{-2}$ & $1.4 \times 10^{-2}$ & 36 & -36 & 0.29 & 0.54 & 0.63 & $8.5 \times 10^{-2}$ \\
\hline LBN & WASI & High & 2796 & 2.8 & $6.9 \times 10^{-2}$ & $5.7 \times 10^{-4}$ & 1.4 & -3.7 & $8.5 \times 10^{-2}$ & 0.69 & 0.78 & $8.7 \times 10^{-2}$ \\
\hline POL & EEUR & High & 3385 & -0.94 & 0.11 & $-4.8 \times 10^{-2}$ & 54 & -68 & 15 & 0.47 & 0.56 & $8.7 \times 10^{-2}$ \\
\hline DNK & NEUR & High & 3239 & -0.70 & -1.1 & $-4.6 \times 10^{-2}$ & 33 & -46 & 15 & 0.64 & 0.72 & $8.7 \times 10^{-2}$ \\
\hline GBR & NEUR & High & 5114 & -2.6 & -3.0 & $4.4 \times 10^{-3}$ & 3.3 & -0.10 & 3.0 & 0.52 & 0.61 & $8.7 \times 10^{-2}$ \\
\hline AUT & WEUR & High & 3278 & $-1.0 \times 10^{-3}$ & 20 & -0.12 & -2.3 & -25 & 7.9 & 0.64 & 0.72 & $8.7 \times 10^{-2}$ \\
\hline FRA & WEUR & High & 5890 & -1.3 & -0.94 & $5.6 \times 10^{-3}$ & 4.2 & -15 & 13 & 0.51 & 0.59 & $8.7 \times 10^{-2}$ \\
\hline DJI & EAFR & Very High & 441 & 7.2 & 4.8 & 0.73 & -1.3 & 6.2 & 3.6 & 21 & 21 & $8.7 \times 10^{-2}$ \\
\hline DZA & NAFR & Very High & 1233 & $7.3 \times 10^{2}$ & 62 & -0.20 & $-3.4 \times 10^{2}$ & $-4.5 \times 10^{2}$ & 1.1 & 1.2 & 1.3 & $8.7 \times 10^{-2}$ \\
\hline EGY & NAFR & Very High & 3206 & 1.4 & $-1.1 \times 10^{-2}$ & $2.9 \times 10^{-2}$ & 32 & -33 & 0.42 & 1.7 & 1.8 & $8.7 \times 10^{-2}$ \\
\hline TUN & NAFR & Very High & 1446 & 9.3 & $2.3 \times 10^{-4}$ & $2.8 \times 10^{-3}$ & -2.3 & -6.6 & 0.43 & 0.83 & 0.91 & $8.6 \times 10^{-2}$ \\
\hline LSO & SAFR & Very High & 45 & 0.11 & 0.86 & $2.5 \times 10^{-2}$ & 0.67 & $9.4 \times 10^{-2}$ & -0.36 & 1.4 & 1.5 & $8.0 \times 10^{-2}$ \\
\hline CPV & WAFR & Very High & 594 & -0.73 & $1.3 \times 10^{-2}$ & 0.18 & 0.36 & 1.1 & $-9.3 \times 10^{-2}$ & 0.83 & 0.92 & $8.7 \times 10^{-2}$ \\
\hline ATG & CARI & Very High & 541 & -0.47 & -2.6 & -0.32 & 3.8 & 1.9 & 0.13 & 2.5 & 2.6 & $8.7 \times 10^{-2}$ \\
\hline BRB & CARI & Very High & 862 & 9.3 & $8.6 \times 10^{-3}$ & $3.7 \times 10^{-2}$ & $1.0 \times 10^{2}$ & $-1.1 \times 10^{2}$ & $2.2 \times 10^{-2}$ & 1.4 & 1.5 & $8.7 \times 10^{-2}$ \\
\hline DMA & CARI & Very High & 341 & -2.0 & -3.8 & -0.12 & 0.27 & 7.5 & -0.58 & 1.2 & 1.3 & $8.4 \times 10^{-2}$ \\
\hline
\end{tabular}


Table A2. Cont.

\begin{tabular}{|c|c|c|c|c|c|c|c|c|c|c|c|c|}
\hline Country & Area & Intensities & SS_CB & $\Delta \mathrm{F} 1 \_\mathrm{CB}$ & $\Delta \mathrm{F} 2 \_\mathrm{CB}$ & $\Delta$ F3_CB & $\Delta \mathrm{F} 4 \_\mathrm{CB}$ & $\Delta \mathrm{F} 5 \_\mathrm{CB}$ & $\Delta \mathrm{F} 6 \_\mathrm{CB}$ & $\Delta \mathrm{Ft} \_\mathrm{CB}$ & WBI_CB & WBI_CB_0 \\
\hline KNA & CARI & Very High & 310 & -7.6 & 2.4 & -0.66 & 12 & 42 & -0.41 & 49 & 49 & $8.6 \times 10^{-2}$ \\
\hline TTO & CARI & Very High & 1142 & -4.4 & -3.2 & $7.3 \times 10^{-4}$ & 0.54 & 7.9 & 0.91 & 1.7 & 1.8 & $8.6 \times 10^{-2}$ \\
\hline IRN & SASI & Very High & 1760 & 0.51 & $-1.1 \times 10^{-2}$ & $1.1 \times 10^{-2}$ & 1.7 & -1.5 & 0.42 & 1.1 & 1.2 & $8.5 \times 10^{-2}$ \\
\hline ISR & WASI & Very High & 2344 & 11 & -1.7 & $-5.4 \times 10^{-2}$ & $3.7 \times 10^{2}$ & $-3.8 \times 10^{2}$ & 4.0 & 2.5 & 2.6 & $8.7 \times 10^{-2}$ \\
\hline JOR & WASI & Very High & 1710 & $1.3 \times 10^{2}$ & 1.3 & 1.4 & -22 & $-1.0 \times 10^{2}$ & 1.4 & 5.8 & 5.8 & $8.7 \times 10^{-2}$ \\
\hline KWT & WASI & Very High & 1161 & $-1.5 \times 10^{3}$ & 6.4 & -5.9 & -36 & $1.5 \times 10^{3}$ & $2.5 \times 10^{2}$ & $3.0 \times 10^{2}$ & $3.0 \times 10^{2}$ & $8.5 \times 10^{-2}$ \\
\hline SAU & WASI & Very High & 1958 & 30 & $1.4 \times 10^{-3}$ & $-4.2 \times 10^{-2}$ & 26 & -45 & 0.80 & 12 & 12 & $8.5 \times 10^{-2}$ \\
\hline ARE & WASI & Very High & 2556 & $1.3 \times 10^{2}$ & $3.0 \times 10^{-2}$ & -4.9 & $7.9 \times 10^{2}$ & $-8.6 \times 10^{2}$ & -17 & 41 & 41 & $8.5 \times 10^{-2}$ \\
\hline YEM & WASI & Very High & 1007 & 72 & $-3.8 \times 10^{-3}$ & 1.7 & -11 & -57 & 0.54 & 5.8 & 5.9 & $8.7 \times 10^{-2}$ \\
\hline MDA & EEUR & Very High & 1417 & -1.3 & 8.7 & 1.3 & $2.1 \times 10^{3}$ & $-2.9 \times 10^{3}$ & $7.8 \times 10^{2}$ & 2.0 & 2.0 & $8.7 \times 10^{-2}$ \\
\hline CZE & EEUR & Very High & 2383 & -16 & 74 & -0.36 & $7.6 \times 10^{2}$ & $-2.9 \times 10^{3}$ & $2.1 \times 10^{3}$ & 11 & 11 & $7.9 \times 10^{-2}$ \\
\hline EST & NEUR & Very High & 1432 & $-1.5 \times 10^{-3}$ & $9.8 \times 10^{2}$ & -0.45 & $6.0 \times 10^{2}$ & $-1.7 \times 10^{3}$ & 83 & 4.0 & 4.1 & $8.7 \times 10^{-2}$ \\
\hline MLT & SEUR & Very High & 1041 & 29 & -2.6 & -0.19 & -10 & -19 & 5.6 & 3.0 & 3.1 & $8.7 \times 10^{-2}$ \\
\hline SVN & SEUR & Very High & 1745 & $-7.4 \times 10^{-3}$ & $1.3 \times 10^{3}$ & -0.34 & 56 & $-5.8 \times 10^{2}$ & $-7.7 \times 10^{2}$ & 2.5 & 2.6 & $8.7 \times 10^{-2}$ \\
\hline DEU & WEUR & Very High & 5860 & -2.9 & 11 & $-7.4 \times 10^{-2}$ & 9.9 & -58 & 42 & 2.7 & 2.8 & $8.7 \times 10^{-2}$ \\
\hline LUX & WEUR & Very High & 889 & -3.3 & $-5.7 \times 10^{2}$ & -1.7 & -50 & -43 & $6.7 \times 10^{2}$ & 5.7 & 5.8 & $8.6 \times 10^{-2}$ \\
\hline
\end{tabular}

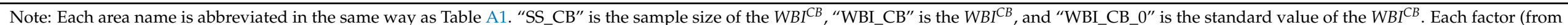

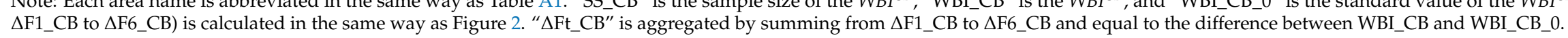




\section{References}

1. Shen, Y.; Oki, T.; Utsumi, N.; Kanae, S.; Hanasaki, N. Projection of future world water resources under SRES scenarios: Water withdrawal. Hydrol. Sci. J. 2008, 53, 11-33. [CrossRef]

2. Hoekstra, A.Y.; Hung, P.Q. Introduction. In Virtual Water Trade: A Quantification of Virtual Water Flows between Nations in Relation to International Crop Trade, Value of Water Research Report Series No.11; UNESCO-IHE: Delft, The Netherlands, 2002 ; pp. 9-12.

3. International Organization for Standardization (ISO). ISO 14046 Briefing Note. Available online: https://www.iso.org/files/live/ sites/isoorg/files/archive/pdf/en/iso14046_briefing_note.pdf (accessed on 27 September 2020).

4. Hoekstra, A.Y.; Chapagain, A.K.; Aldaya, M.M.; Mekonnen, M.M. Water Footprint Accounting. In The Water Footprint Assessment Manual-Setting the Global Standard; Earthscan: London, UK, 2011; pp. 19-72.

5. Raskin, P.; Glelck, P.; Kirshen, P.; Pontius, G.; Strzepek, K. Future Water Stress and Vulnerability. In Comprehensive Assessment of the Freshwater Resources of the World; Water Futures: Assessment of Long-Range Patterns and Problems; Stockholm Environment Institute: Stockholm, Sweden, 1997; pp. 22-39.

6. Hanasaki, N.; Kanae, S.; Oki, T.; Masuda, K.; Motoya, K.; Shirakawa, N.; Shen, Y.; Tanaka, K. An integrated model for the assessment of global water resources-Part 2: Applications and assessments. Hydrol. Earth Syst. Sci. 2008, 12, $1027-1037$. [CrossRef]

7. Alcamo, J.; Flörke, M.; Märker, M. Future long-term changes in global water resources driven by socio-economic and climatic changes. Hydrol. Sci. J. 2007, 52, 247-275. [CrossRef]

8. Sun, S.; Wang, Y.; Engel, B.A.; Wu, P. Effects of virtual water flow on regional water resources stress: A case study of grain in China. Sci. Total Environ. 2016, 550, 871-879. [CrossRef]

9. Hoekstra, R.; van der Bergh, J.J.C.J.M. Comparing structural and index decomposition analysis. Energy Econ. 2003, 25, 39-64. [CrossRef]

10. Ang, B.W.; Liu, F.L. A new energy decomposition method: Perfect in decomposition and consistent in aggregation. Energy 2001, 26, 537-548. [CrossRef]

11. Sun, J.W. Changes in energy consumption and energy intensity: A complete decomposition model. Energy Econ. 1998, 20, 85-100. [CrossRef]

12. Sun, J.W.; Malaska, P. CO 2 emission intensities in developed countries 1980-1994. Energy 1998, 23, 105-112. [CrossRef]

13. Ang, B.W.; Liu, F.L.; Chew, E.P. Perfect decomposition techniques in energy and environmental analysis. Energy Policy 2003, 31, 1561-1566. [CrossRef]

14. Mishina, Y.; Muromachi, Y. Regional decomposition analysis of $\mathrm{CO}_{2}$ emissions from passenger cars and trucks in Japan from 1999 to 2008. J. Jpn. Soc. Civ. Eng. Ser. D3 Infrastruct. Plan. Manag. 2011,67, I_89-I_100. (In Japanese)

15. Mishina, Y.; Muromachi, Y. Carbon dioxide emissions from Japanese passenger cars up to 2020: Projection using modified Lapeyres decomposition techniques. J. East Asia Soc. Transp. Stud. 2013, 10, 1157-1170.

16. Ang, B.W. Decomposition analysis for policymaking in energy: Which is the preferred method? Energy Policy 2004, 32, 1131-1139. [CrossRef]

17. Xu, Y.; Huang, K.; Yu, Y.; Wang, X. Changes in water footprint of crop production in Beijing from 1978 to 2012 : A logarithmic mean Divisia index decomposition analysis. J. Clean. Prod. 2015, 87, 180-187. [CrossRef]

18. Zhao, C.; Chen, B. Driving force analysis of the agricultural water footprint in China based on the LMDI method. Environ. Sci. Technol. 2014, 48, 12723-12731. [CrossRef]

19. Zou, M.; Kang, S.; Niu, J.; Lu, H. A new technique to estimate regional irrigation water demand and driving factor effects using an improved SWAT model with LMDI factor decomposition in an arid basin. J. Clean. Prod. 2018, 185, 814-828. [CrossRef]

20. Zhang, Z.; Shi, M.; Yang, H. Understanding Beijing's water challenge: A decomposition analysis of changes in Beijing's water footprint between 1997 and 2007. Environ. Sci. Technol. 2012, 46, 12373-12380. [CrossRef] [PubMed]

21. Wang, X.; Huang, K.; Yu, Y.; Hu, T.; Xu, Y. An input-output structural decomposition analysis of changes in sectoral water footprint in China. Ecol. Indic. 2016, 69, 26-34. [CrossRef]

22. Feng, L.; Chen, B.; Hayat, T.; Alsaedi, A.; Ahmad, B. The driving force of water footprint under the rapid urbanization process: A structure decomposition analysis for Zhangye city in China. J. Clean. Prod. 2017, 163, S322-S328. [CrossRef]

23. Sun, S.; Fu, G.; Bao, C.; Fang, C. Identifying hydro-climatic and socioeconomic forces of water scarcity through structural decomposition analysis: A case study of Beijing city. Sci. Total Environ. 2019, 687, 590-600. [CrossRef]

24. Zhang, C.; Wu, Y.; Yu, Y. Spatial decomposition analysis of water intensity in China. Socio-Econ. Plan. Sci. 2020, 69, 100680. [CrossRef]

25. Yamaguchi, Y.; Yoshikawa, N.; Amano, K.; Hashimoto, S. Evaluation of current freshwater requirement in Asia based on global food trade and food supply-demand balances. Asia Jpn. Res. Acad. Bull. 2019, 1, 11.

26. Stone, R.; Bates, J.; Bacharach, M. Changing Coefficients. In Input-Output Relationships 1954-1966, A Programme for Growth; Chapman and Hall Ltd.: London, UK, 1963; Volume 3, pp. 24-41.

27. Food and Agriculture Organization of the United Nations (FAO). Concepts and Definitions Used in Food Balance Sheets. In Food Balance Sheet: A Handbook; FAO: Rome, Italy, 2001; pp. 8-18.

28. Mekonnen, M.M.; Hoekstra, A.Y. National Water Footprint Accounts: The Green, Blue and Grey Water Footprint of Production and Consumption, Value of Water Research Report Series No. 50; UNESCO-IHE: Delft, The Netherlands, 2011; Volume 2. 
29. Döll, P.; Siebert, S. Global modeling of irrigation water requirements. Water Resour. Res. 2002, 38, 8-1-8-10. [CrossRef]

30. Smakhtin, V.; Revenga, C.; Döll, P. Data and Methodology. In Taking into Account Environmental Water Requirements in Global-Scale Water Resources Assessments, Comprehensive Assessment of Water Management in Agriculture Research Report 2; Comprehensive Assessment Secretariat: Colombo, Sri Lanka, 2004; pp. 3-10.

31. FAO. FAOSTAT: Food Balances: Commodity Balances-Crops Primary Equivalent, 2009-2011. Available online: http://www.fao. org/faostat/en/\#data/BC (accessed on 19 January 2018).

32. FAO. FAOSTAT: Food Balances: Commodity Balances-Livestock and Fish Primary Equivalent, 2009-2011. Available online: http:/ / www.fao.org/faostat/en/\#data/BL (accessed on 19 January 2018).

33. FAO. FAOSTAT: Trade: Detailed Trade Matrix, 2009-2011. Available online: http://www.fao.org/faostat/en/\#data/TM (accessed on 1 April 2017).

34. FAO. AQUASTAT, 2009-2011. Available online: http://www.fao.org/nr/water/aquastat/data/query/index.html?lang=en (accessed on 9 May 2017).

35. Ministry of Education, Culture, Sports, Science and Technology (MEXT). Standard Tables of Food Composition in Japan-2010. Available online: https:/ / www.mext.go.jp/b_menu/shingi/gijyutu/gijyutu3/houkoku/1298713.htm (accessed on 27 March 2018). (In Japanese)

36. MEXT. Standard Tables of Food Composition in Japan-2015—(Seventh Revised Version). Available online: https://www.mext. go.jp/a_menu/syokuhinseibun/1365297.htm (accessed on 26 July 2019). (In Japanese)

37. United States Department of Agriculture (USDA). FoodData Central-USDA. Available online: https://fdc.nal.usda.gov/ (accessed on 16 October 2019).

38. INRAE-CIRAD-AFZ. Tables of Composition and Nutritional Values of Feed Materials INRA CIRAD AFZ. Available online: https: / / www.feedtables.com/ (accessed on 13 October 2019).

39. Japan Association for International Collaboration of Agriculture and Forest (JAICAF). "Nishi Afurika no nōgyō to mamerui" [Agriculture and Beans of West Africa]. In "Nishi Afurika ni okeru mamerui no seisan kara ryūtū made—Benan Kyōwakoku no jirei kara ikinai shijō to chīki jūmin no seikatsu kōjōo kangaeru" [From Production to Distribution of Beans in West Africa-Thinking Intra-Regional Market and Life Improvement of Local Residents from the Case of the Republic of Benin]; JAICAF: Tokyo, Japan, 2007; pp. 3-52. (In Japanese)

40. Agricultural \& Livestock Industries Corporation (ALIC). Statistical Data Regarding Supply-Demand Relationship of Livestock. Available online: https:/ / www.alic.go.jp/joho-c/joho05_000073.html (accessed on 9 October 2019). (In Japanese)

41. FAO. FAOSTAT: Population: Annual Population, 2010. Available online: http://www.fao.org/faostat/en/\#data/OA (accessed on 24 September 2019).

42. FAO. Introduction. In The FAO Statistics Quality Assurance Framework; FAO: Rome, Italy, 2014; p. 5. 